\title{
A STUDY OF THE IMPACTS OF THE DEVELOPED BUILDING REGULATION ON THE THERMAL PERFORMANCE OF RESIDENTIAL BUILDINGS IN RIYADH- SAUDI ARABIA
}

\author{
Mohammad Ghazi Kotbi* and Saleh Mubarak Baharetha \\ Architecture and Building Sciences Department, Faculty of Architecture and Planning, \\ King Saud University, Al Riyadh, Saudi Arabia \\ *Corresponding Author E-mail: mkotbi@ksu.edu.sa
}

\begin{abstract}
Building regulations are one of the important tools that improve urban environment due to their rules and standards which control the relationship between buildings within their urban pattern. Riyadh city is characterized by it's hot and dry climate, which requires compatible climatic treatment with its desert environment. The compact pattern of traditional buildings of Riyadh constituted a good example of the compatibility and adaptation of the building with its surrounding environment, starting from the layout of the building and ending by its relationship with the surrounding urban pattern. The changes in the size of the urban development has led to import building regulations from different environments that has different climate of Riyadh. As a result, the imported building regulations caused negative impacts to thermal performance of residential buildings in Riyadh and consequently the energy consumption has witnessed a dramatic increase.
\end{abstract}

The developed building regulation which was released in 2018, has made several modifications to the previous building regulation in terms of the rear and side setbacks of building's first floor. So, it is of great importance to evaluate this building regulation to investigates its impacts on the thermal performance of buildings. The main aim of this research is investigating the impacts of the developed building regulation on the thermal performance of residential buildings in Riyadh.

The methodology adopted for achieving the aim of this research consists of two phases. First, a literature review was conducted to investigate the development of urban growth and building regulations in Riyadh. Second, residential buildings energy simulation was carried out to examine the impacts of the developed building regulation on the thermal performance residential buildings. At the end, the study come up with some results and recommendations that will contribute to boost environmental aspects in buildings regulations and improve residential building's thermal performance in Riyadh city.

\section{KEYWORDS: Building Regulations, Residential Buildings, Thermal Performance, Energy Consumption, Urban Sustainability}




\title{
دراسة تأثير النظام المطور للبناء في المملكة على الأداء الحراري للمباني السكنية في مدينة الرياض بالمملكة العربية السعودية المبراية
}

\author{
محمد غازي كتبي* و صالح مبارك باحارثه

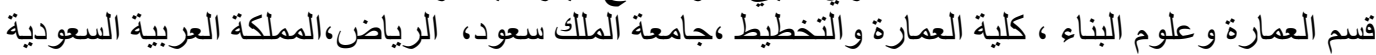

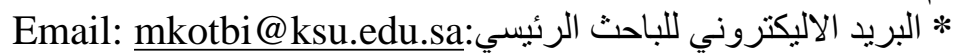

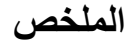

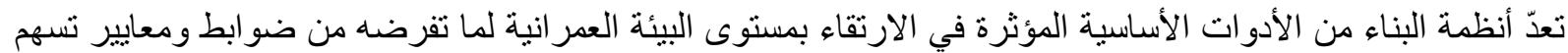

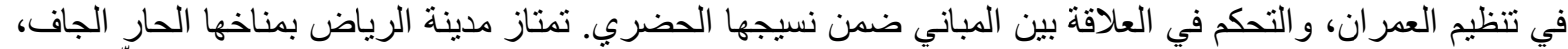

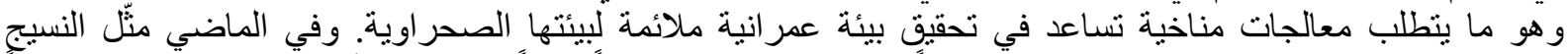

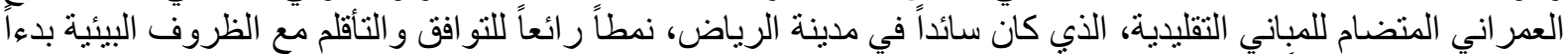

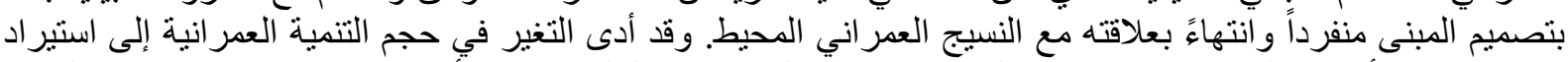

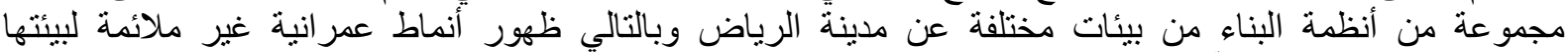

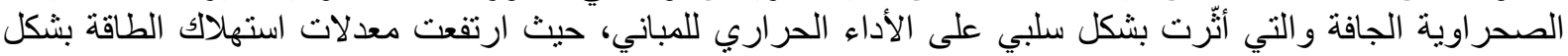

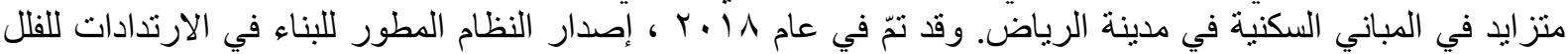

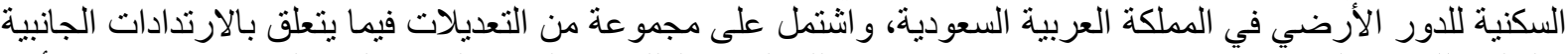

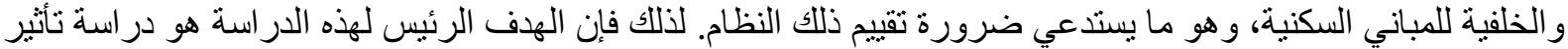

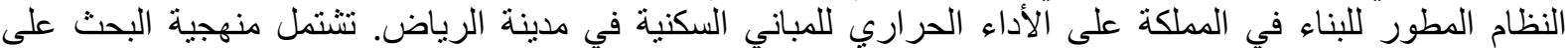

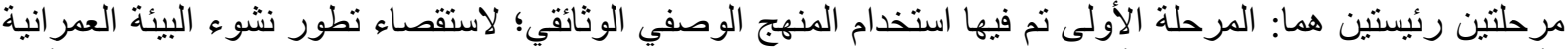

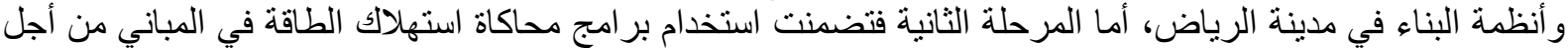

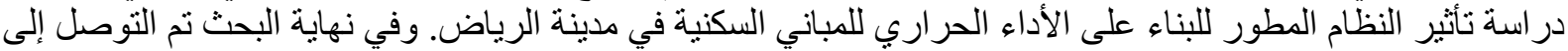

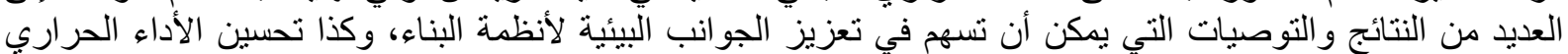
للمباني السكنية في مدينة الرياض.

الكلمات المفتاحية : أنظمة البناء، المباني السكنية، الأداء الحراري، استهلاك الطاقة، الاستدامة العمرانية

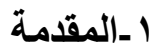

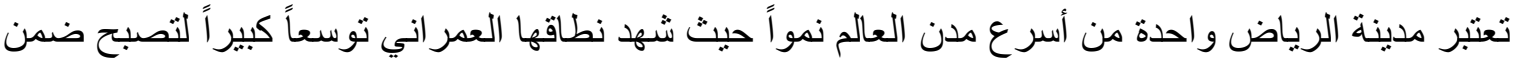

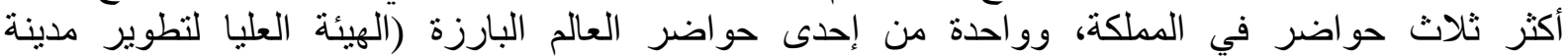

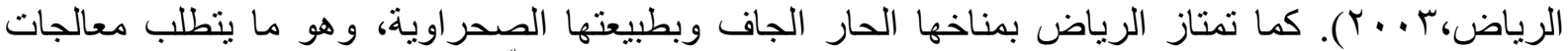

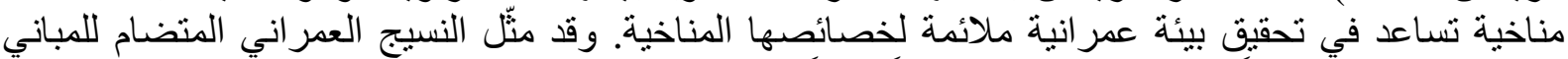

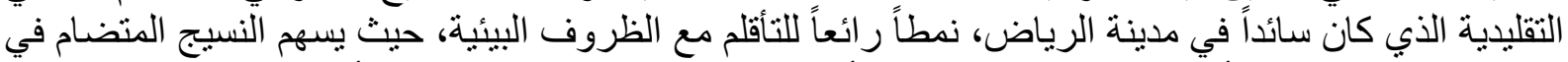

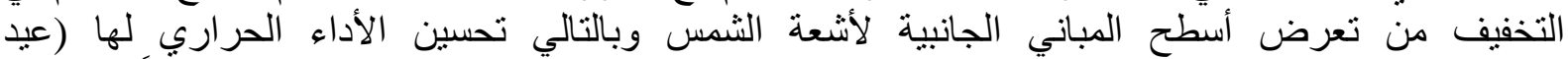
ويوسف، ؟ . • ؟). وقد اعتمدت عمارة المساكن الطينية في المناطق الحارة الجافة على توفير الظل ذاتياً من خلال

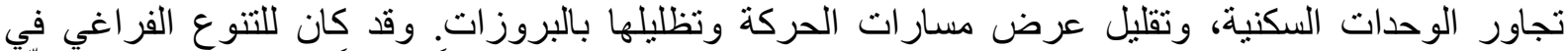

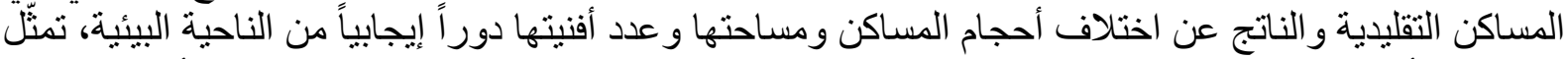

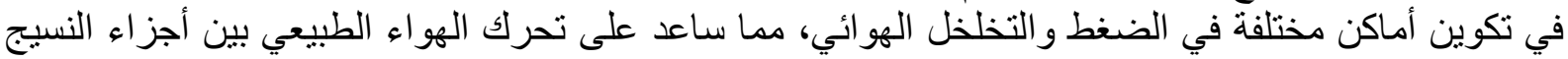

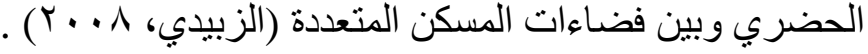

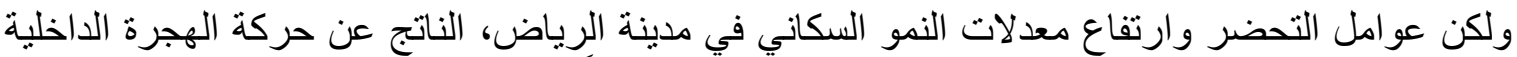
و الخارجية، أدت إلى التخلي عن النمط التقليدي المتضام الذي كان سائداً في المدينة، والبحت البحث عن بديل آخر يسرع

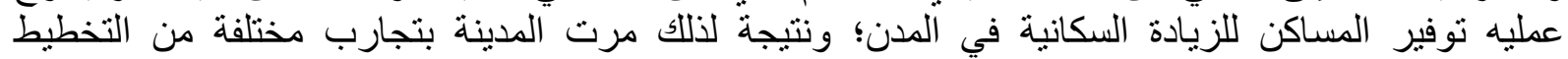

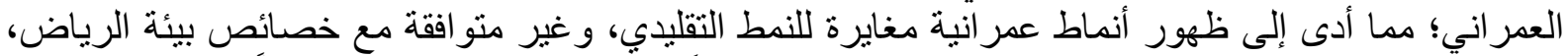
فظهر النمط الثبكي للمناطق السكنية، وأصبح المسكن مطلاً أكثر على الخارج، ومئه ومعرضاً للعوامل المناخية

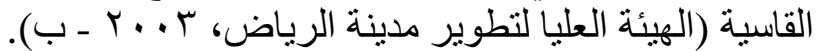


أسهمت مجمو عة من العو امل في ظهور البيئة العمر انية المعاصرة للمناطق السكنية في مدينة الرياض، التهنة منها

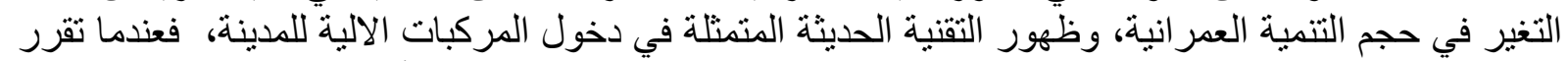

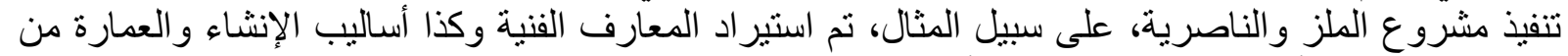

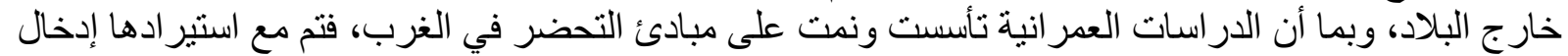

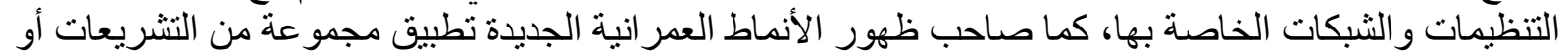

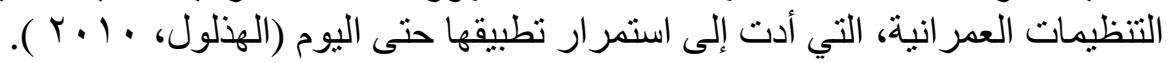

تهدف أنظمة البناء بشكل رئيس إلى تنظيم العمران في التجمعات العمر انية بجميع أشكالها المختلفة سواء التهاء

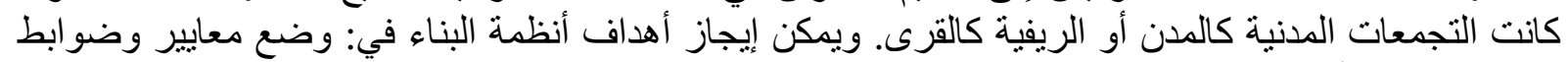

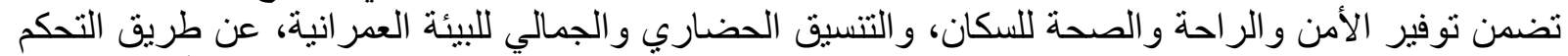

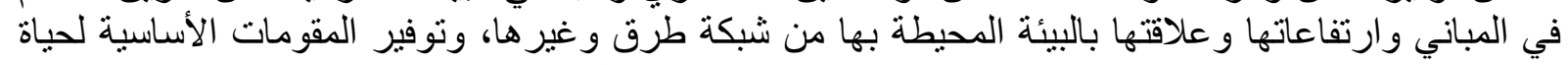

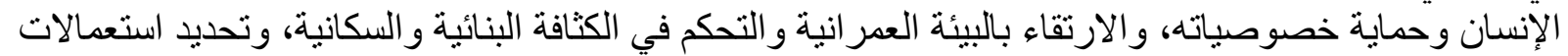

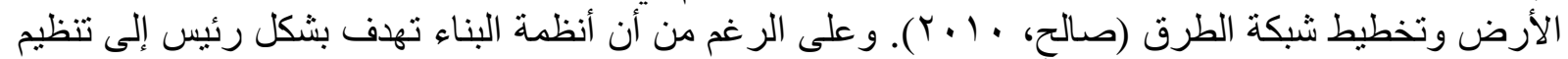

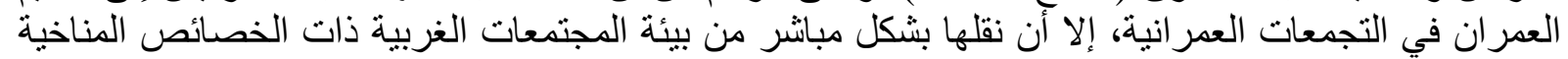

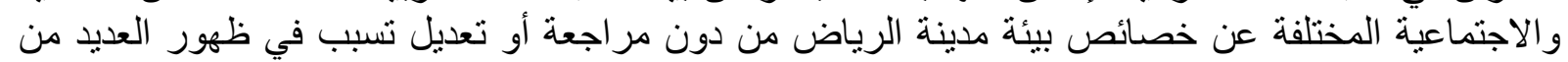

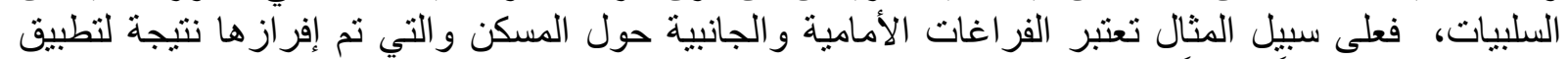

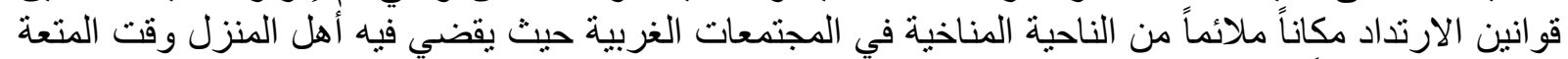

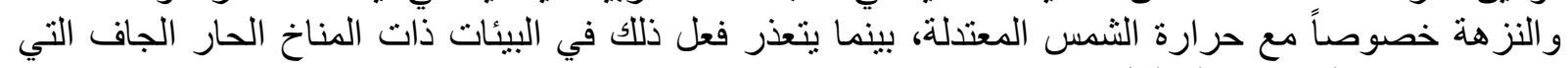

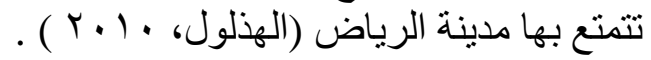

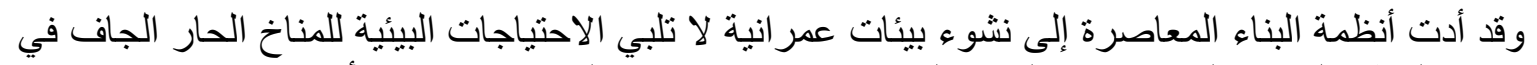

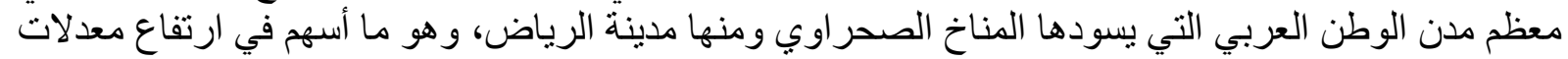

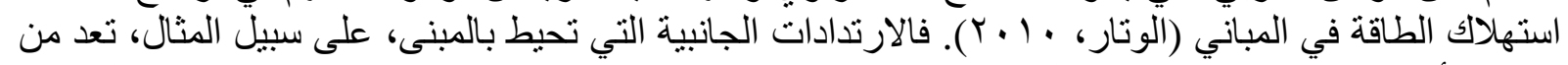

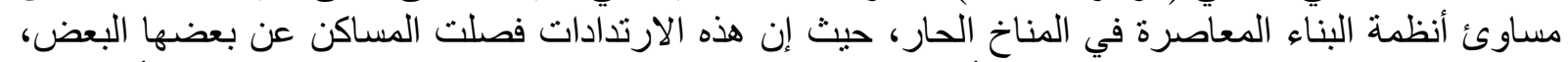

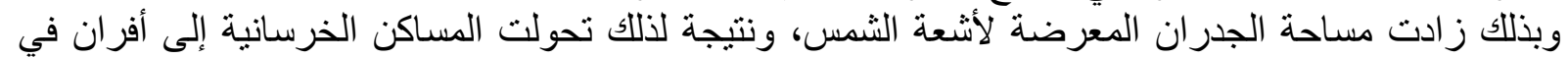

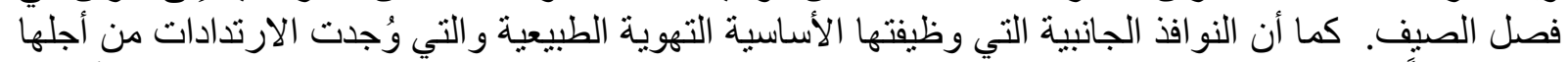

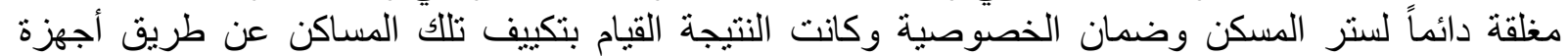

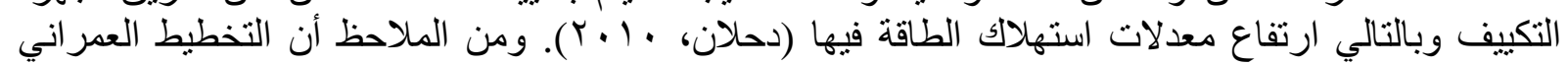

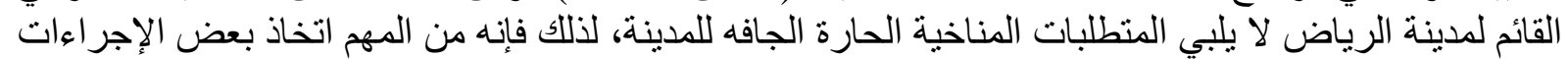

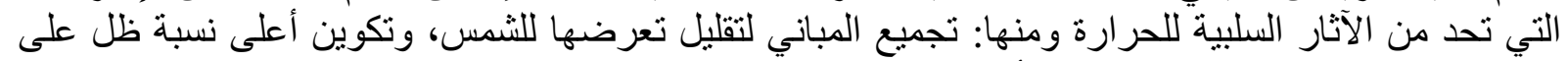

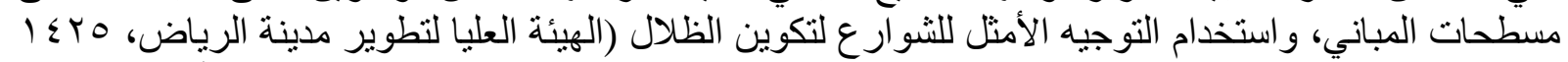

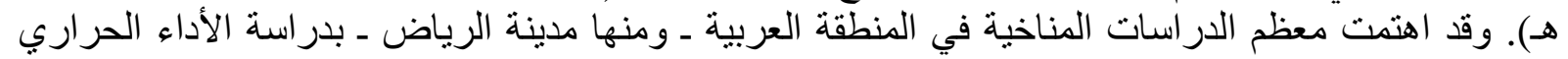

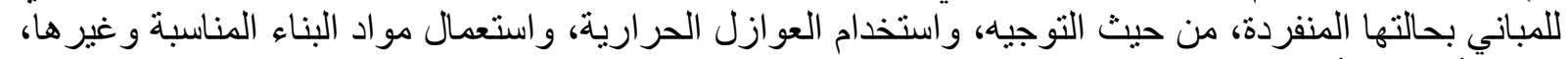

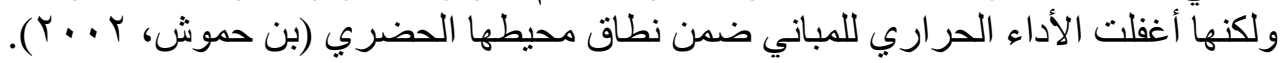

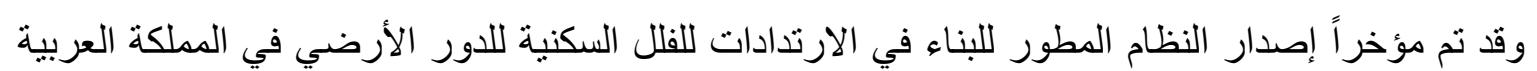

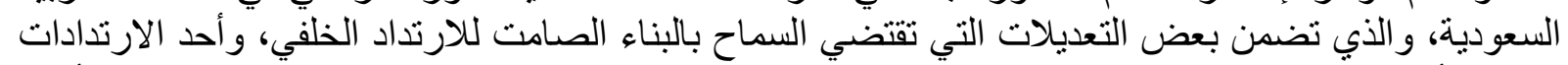

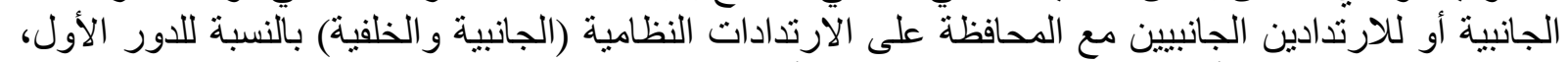
و هو ما يستدعي اختبار تأثثير ذلك النظام المطور على الأداء الحراري للمباني السكنية في مدينة الرياض.

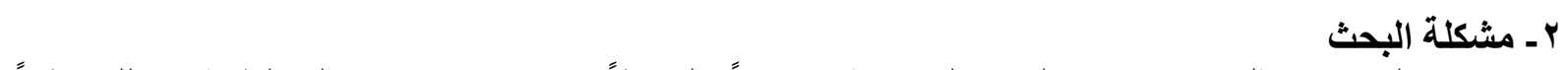
تشهر الرياض مثل غير ها من المدن السعودية ارتفاعاً ملحوظاً في معدلات استهلاك الطاقة، وذلك نظراً

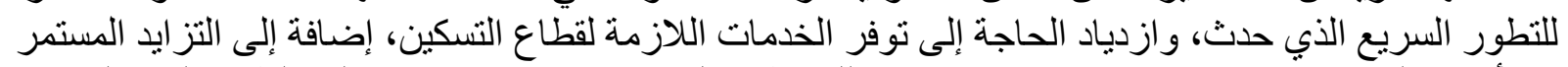

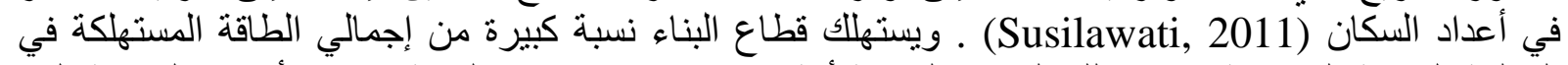

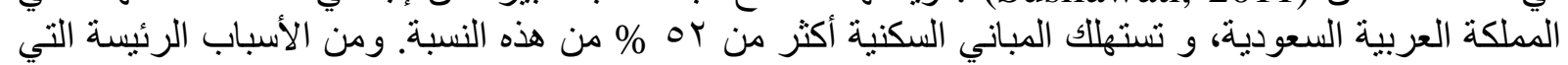

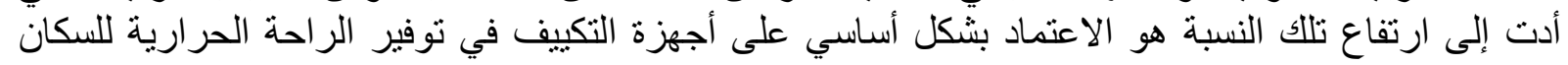


حيث إن أكثر من · V \% من اجمالي الطاقة المستهكة في القطاعين السكني والحكومي يتم استهلاكها في أجهزة

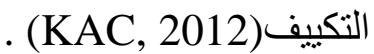

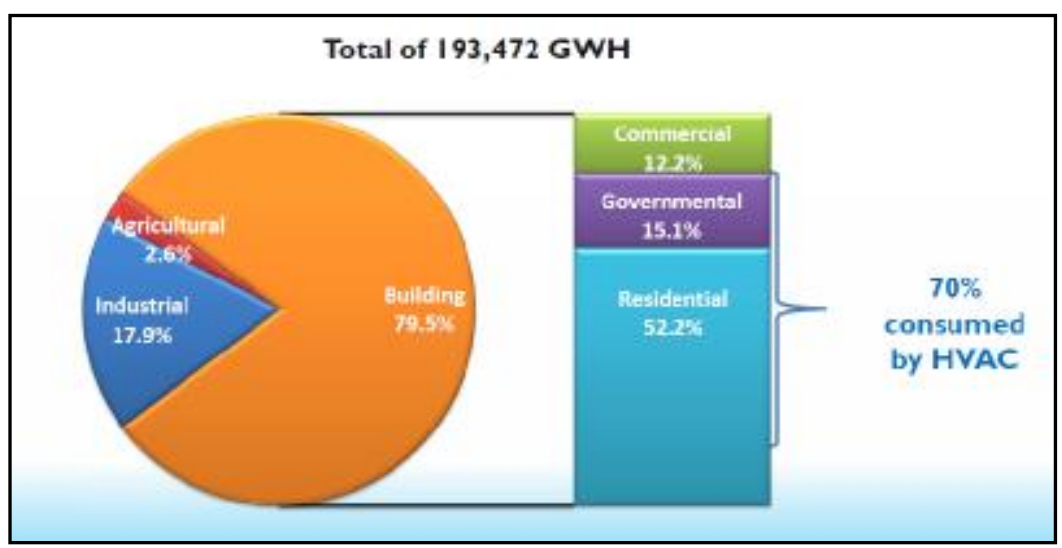

شكل ا ـ أنماط استهلاك الطاقة في المملكة العربية السعودية. المصدر

(SEC, 2009).

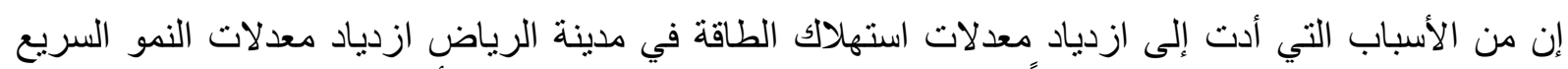
للمنطقة العمر انية في المدينة خصوصاً في الاطر اف، ويشكل الاستعمال السكني أكبر نسبة نمو في الإنة الاستعمالات

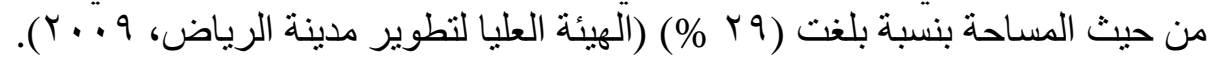

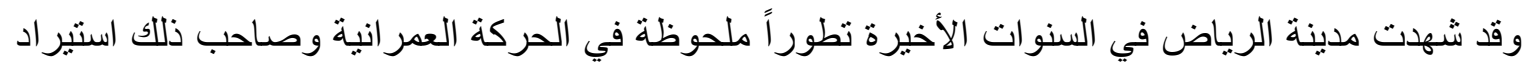

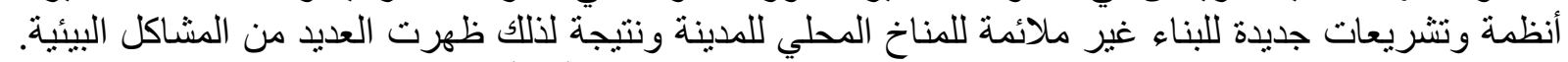

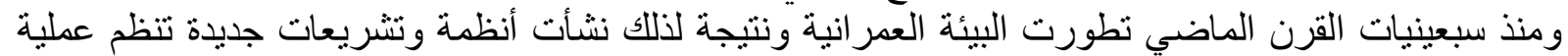

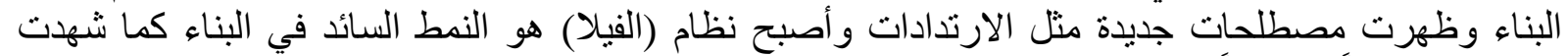

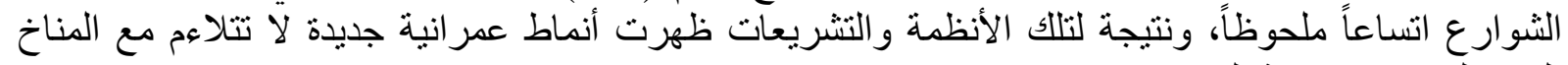
الحار الجاف في مدينة الرياض (Al-Hemaidi, 2001)

وقد يكون من أحد الأسباب التي أدت إلى ارتفاع معدلات استهالاك الطاقة في المباني السكنية في مدينة

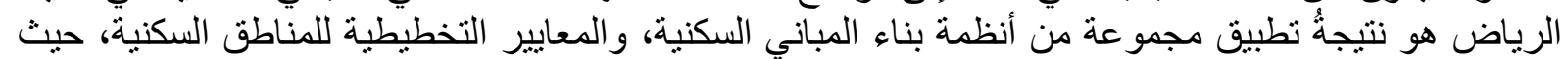

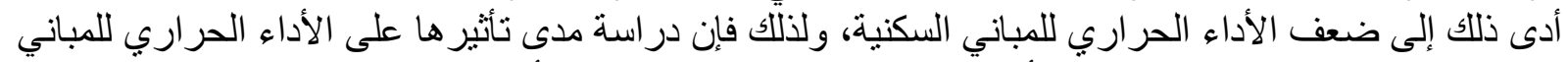

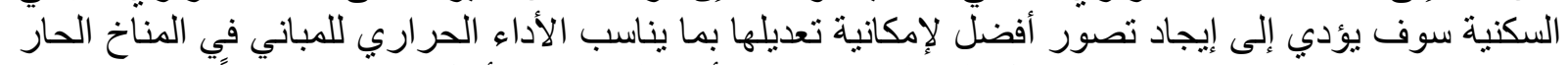

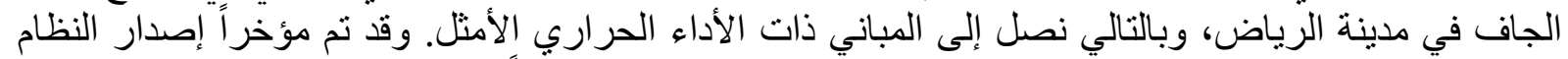

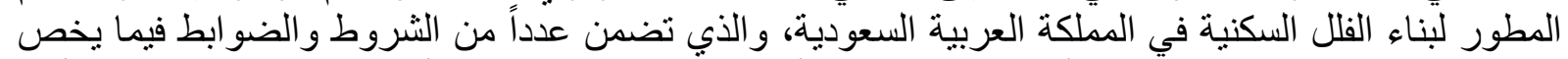

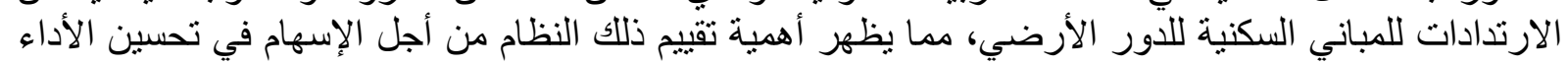

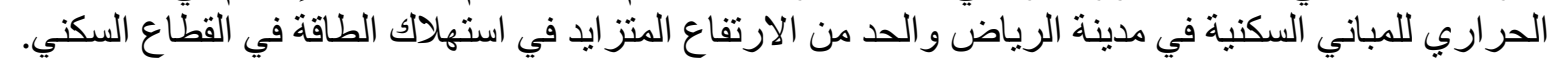

\section{بـ - مدف البحث وأهميته}

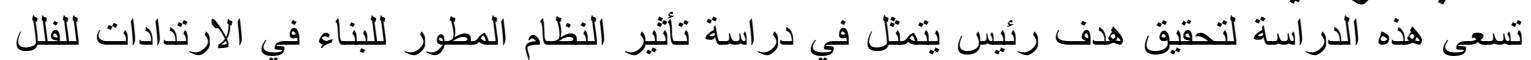

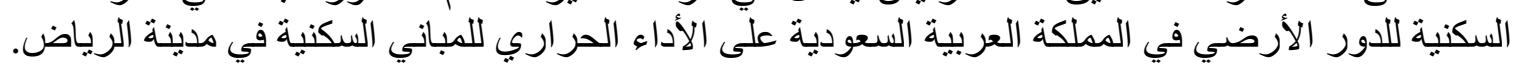

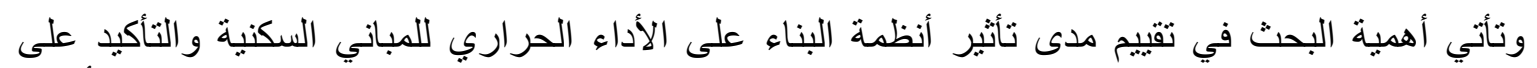

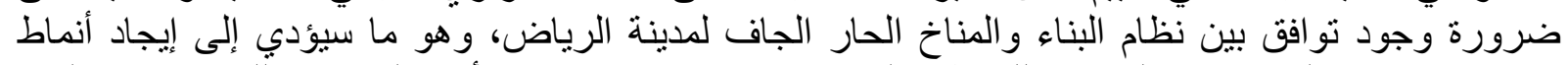

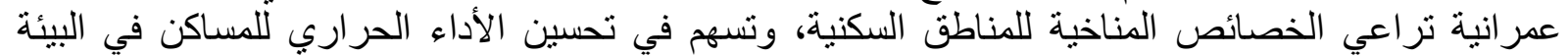

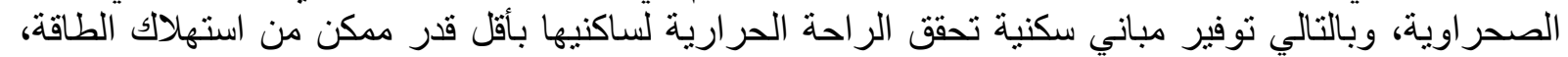
وبأقل آثار سلبية على البيئة المحيطة، وسينخفض نئية نتيجة لذلك استهلاك الطاقة في المباني السكنية. 


$$
\text { ـ ـمنهجية البحث منهجية البحث على مرحلتين هما: }
$$

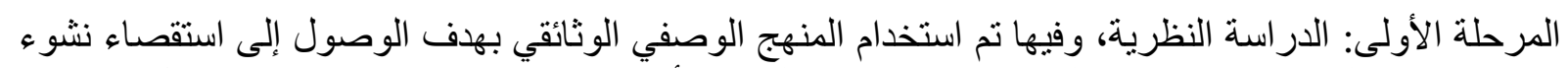

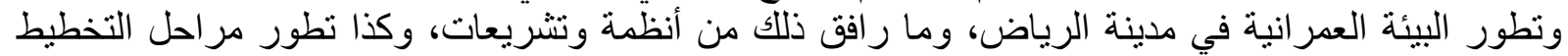

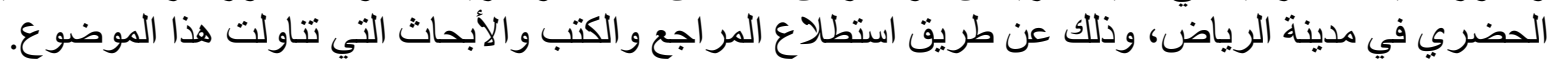

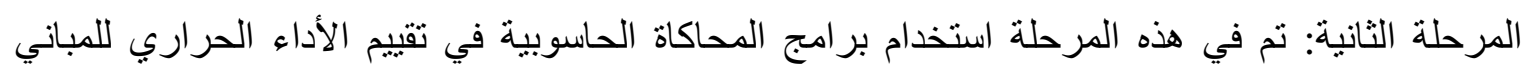

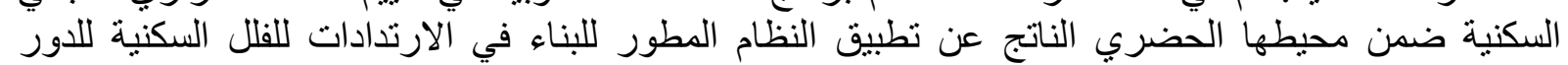

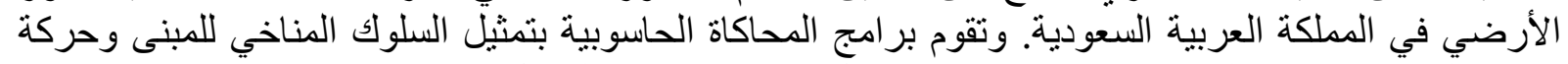

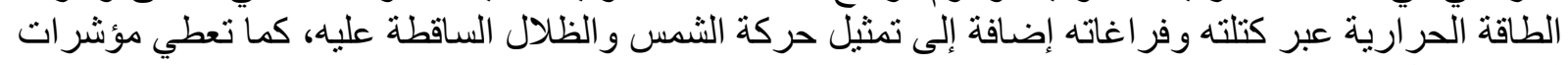

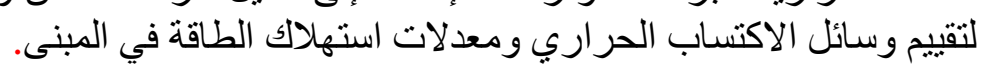

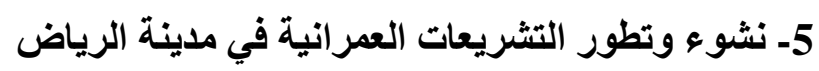

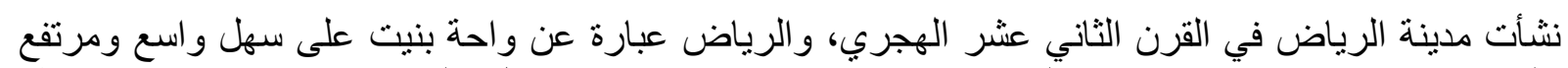

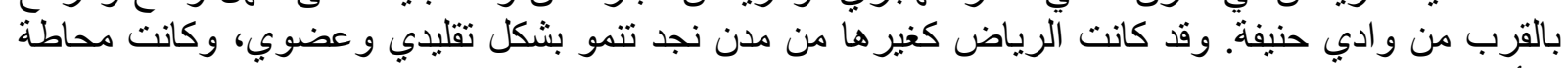

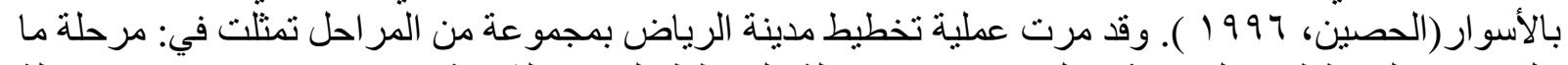

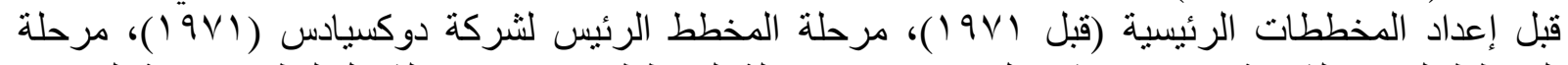

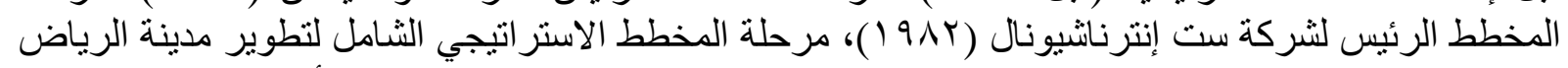

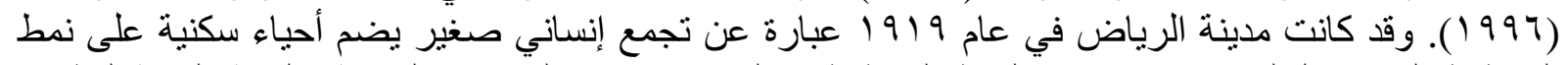

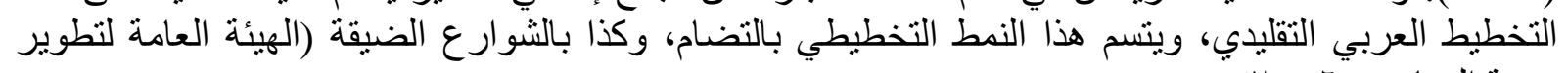

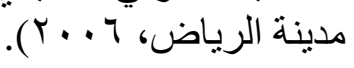

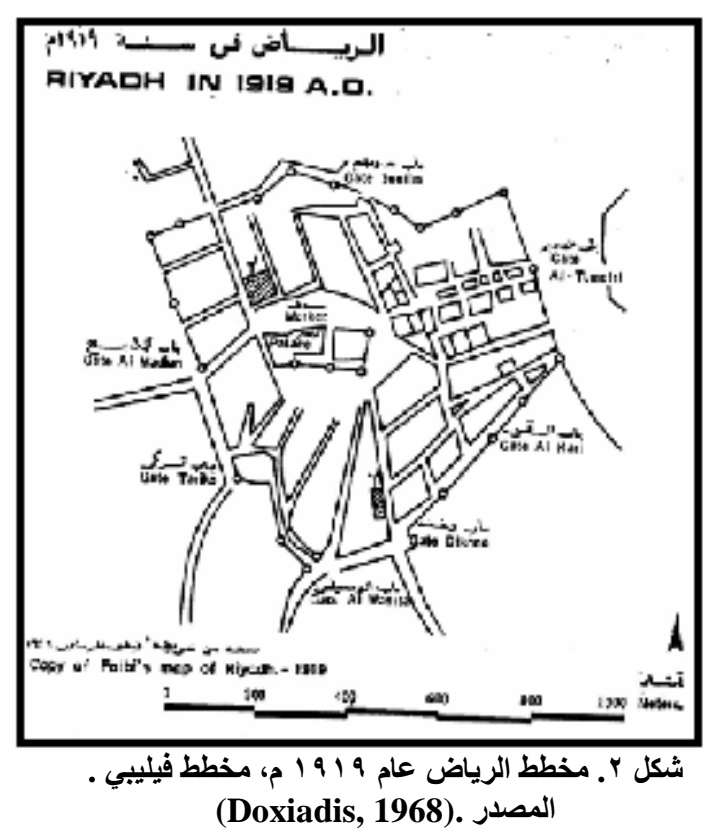

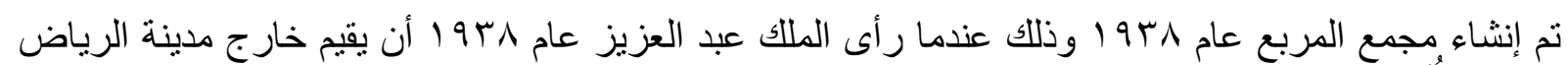

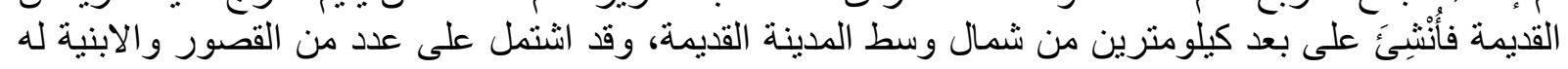

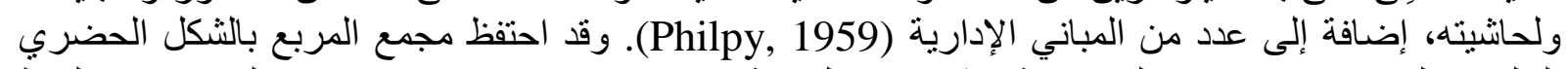

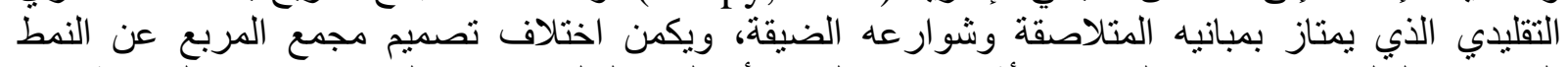

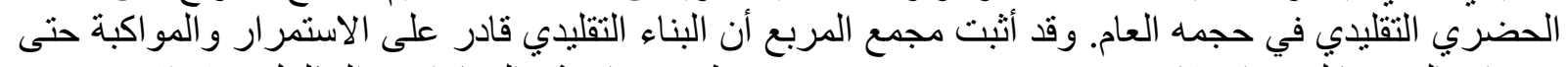

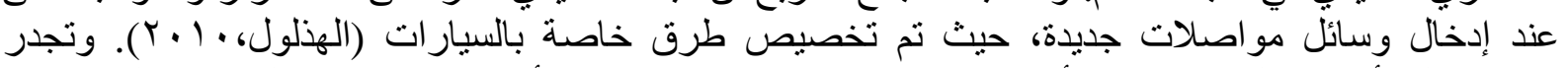

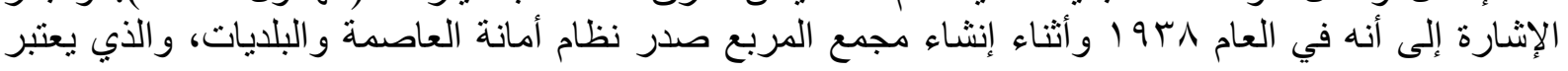


بداية مفهوم تخطيط المدن، حيث تم فيه تحديد مسؤولية البلديات وتخويلها بوضع الأنظمة النئ العمر انية واشتر اطات

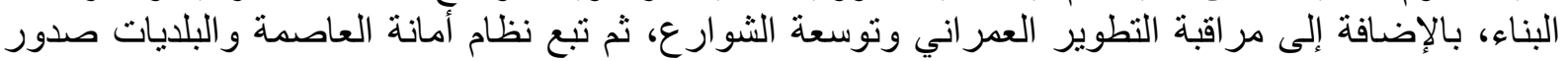

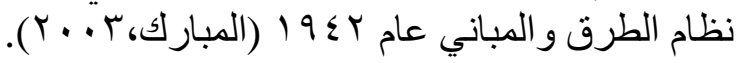

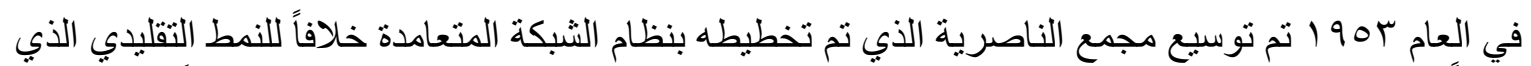

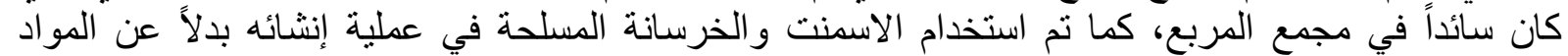

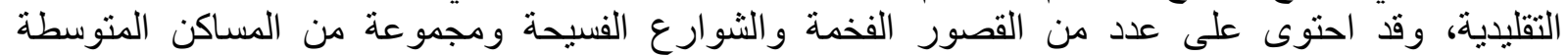

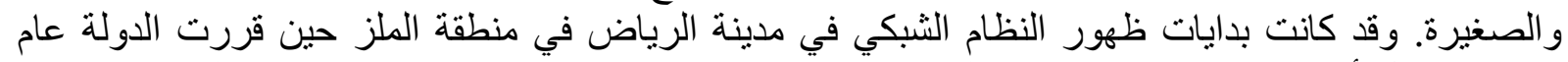

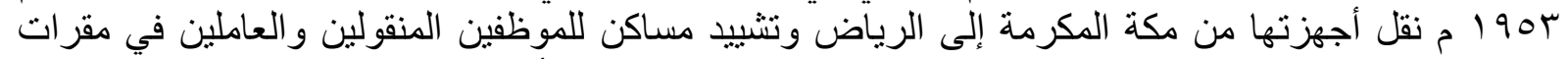

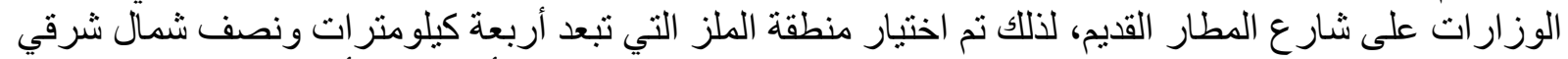

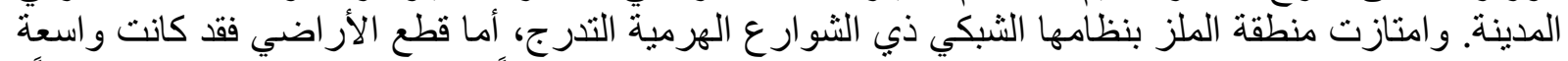

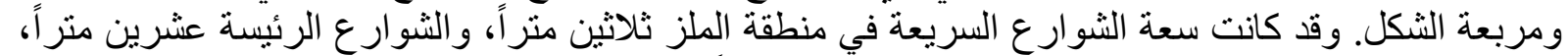

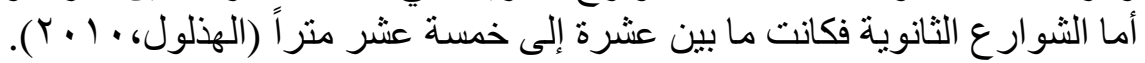

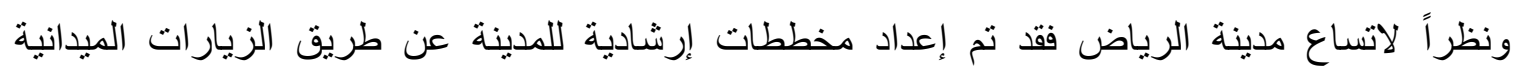

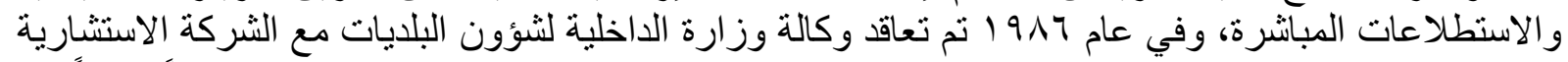

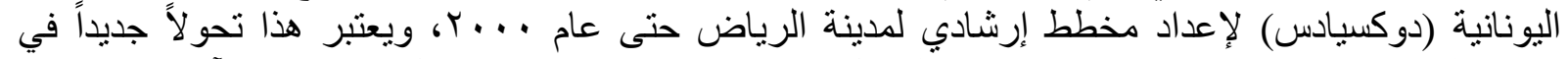

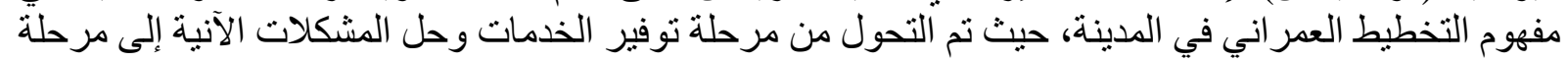

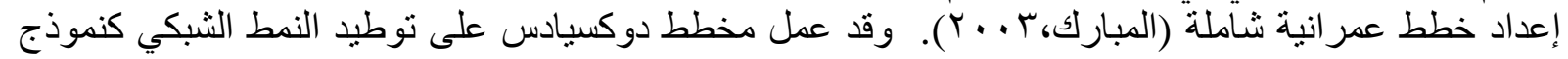

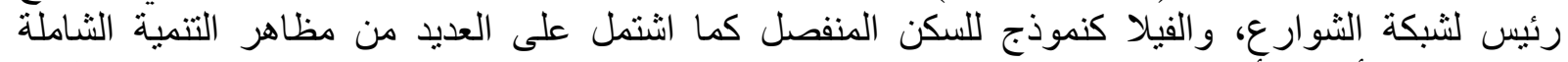

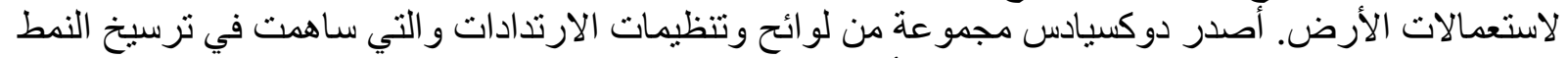

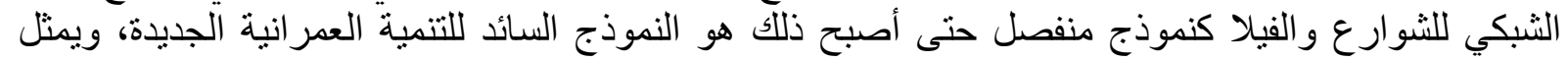

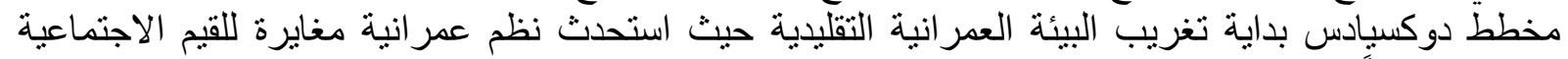

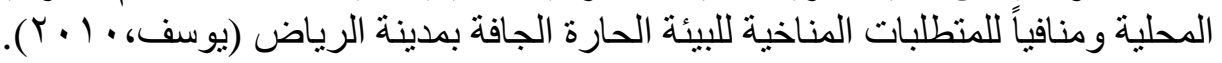

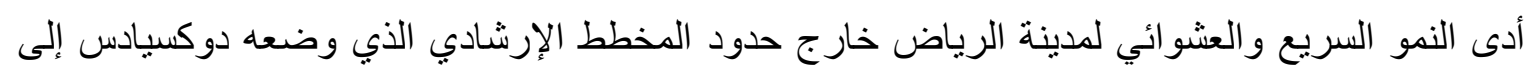

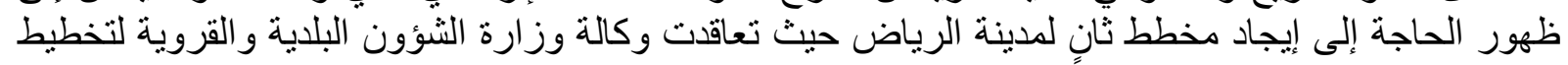

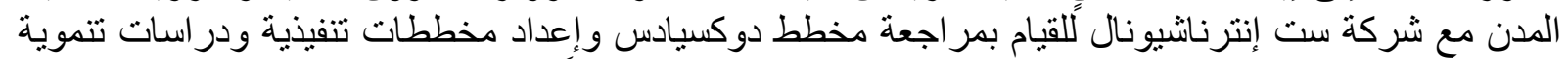

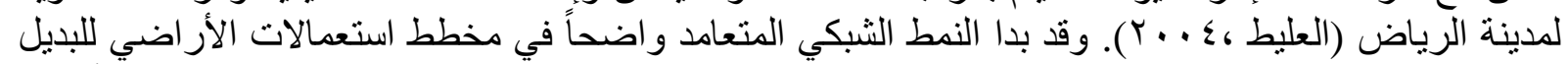

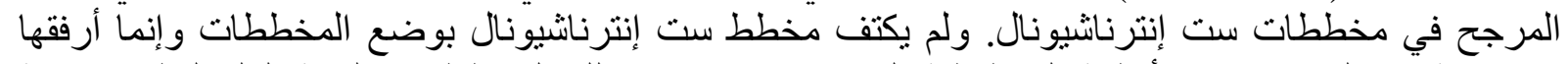
بمجموعة من التشريعات والأنظمة التخطيطية التي تساعد في تنفيذ تلك المخططات (الهيئة العليا لنطوير مدينة

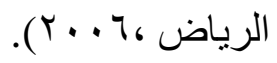

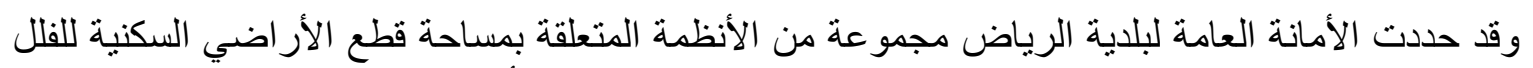

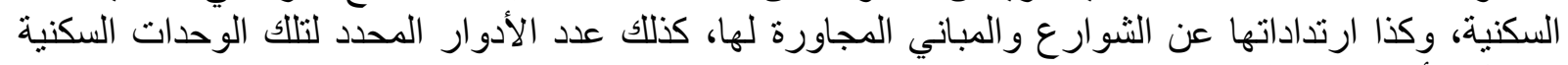

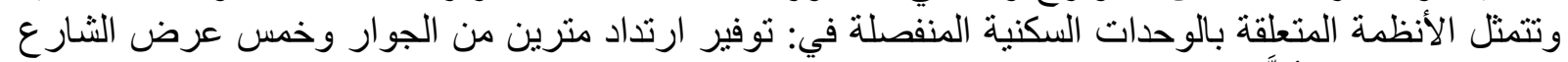

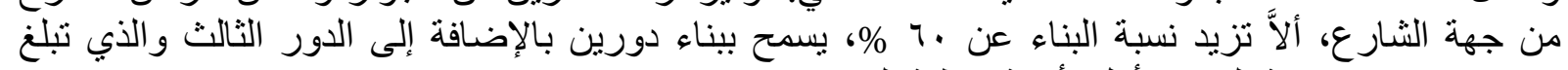

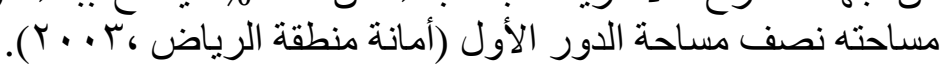

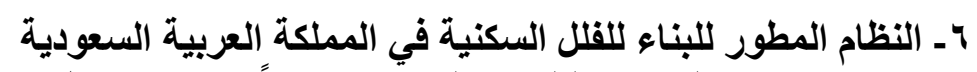

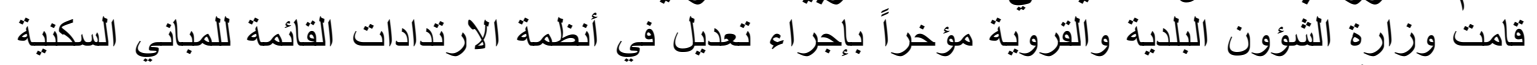

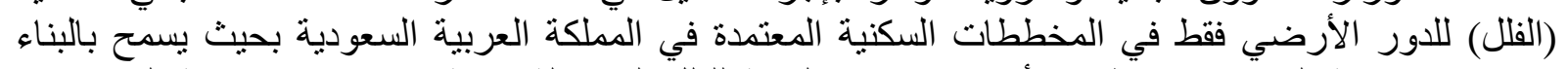

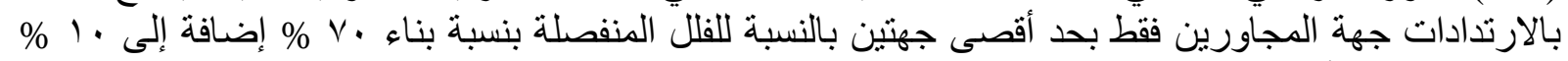

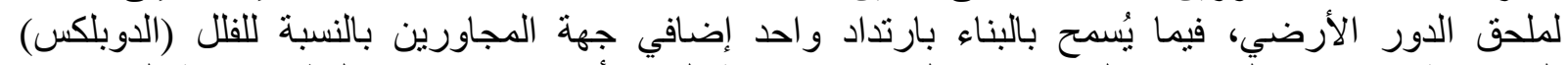

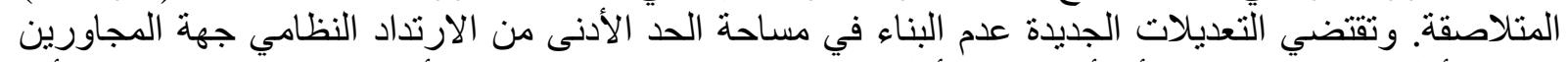

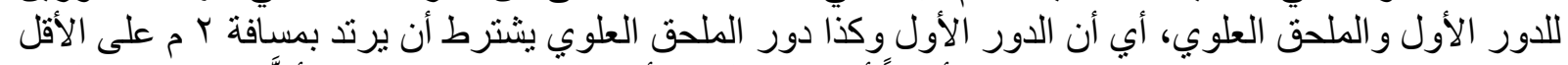

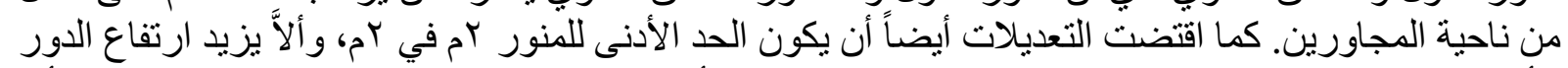

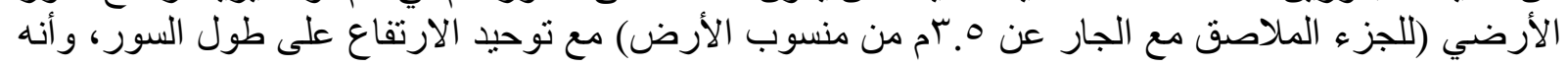


في حال وجود جار قائم فيلزم المستفيد بتشطيب الجزء الظاهر للمجاورين بنفس المو اد المستخدمة لديهم (وزارة

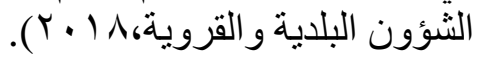

\section{V- بناء النموذج السكني محل الدراسة}

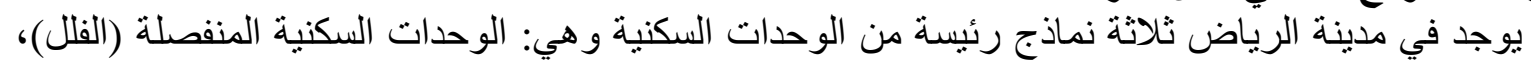

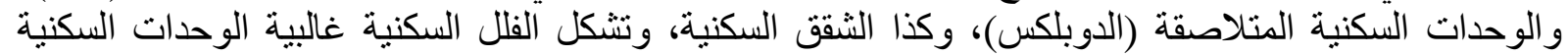

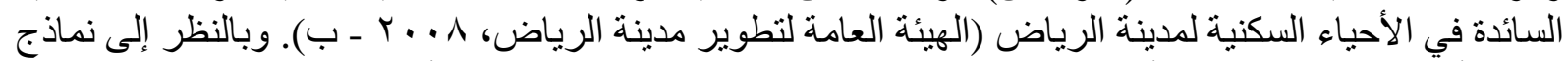

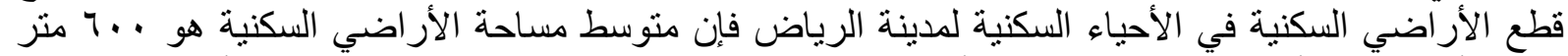

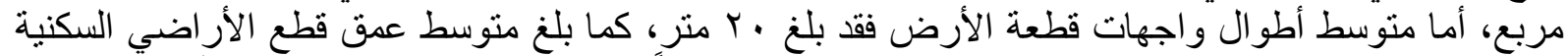

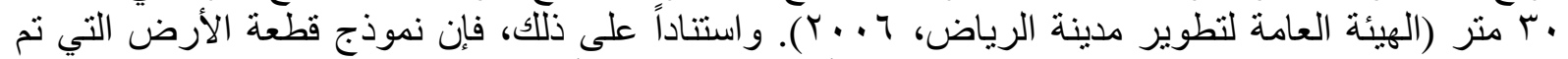

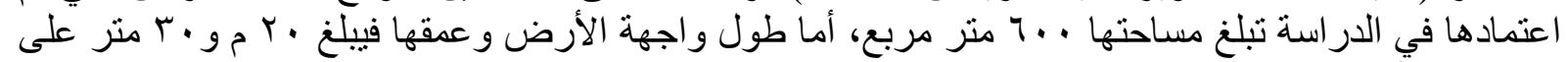

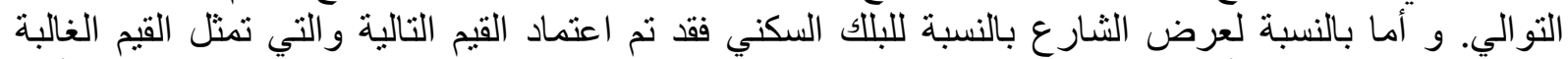

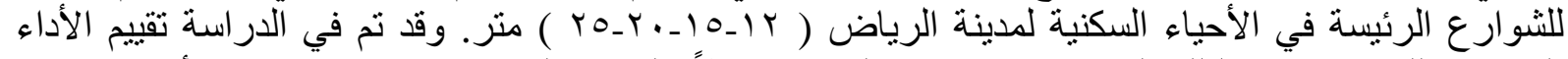

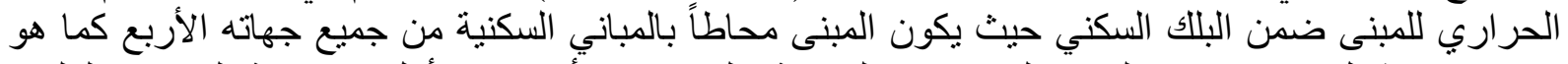

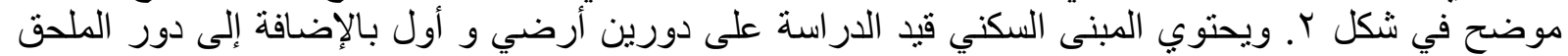

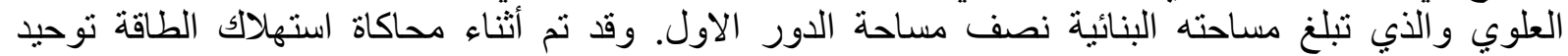

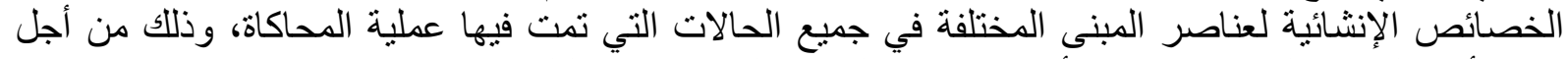

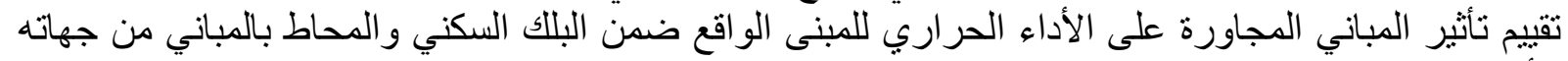
الأربع.

\section{0}
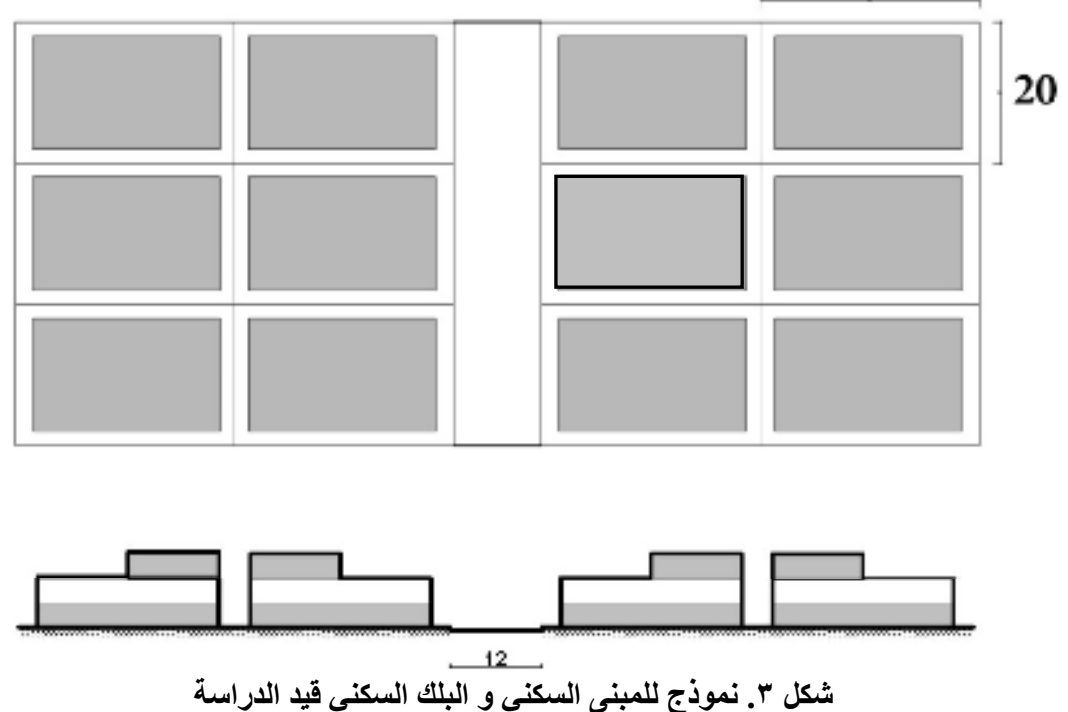

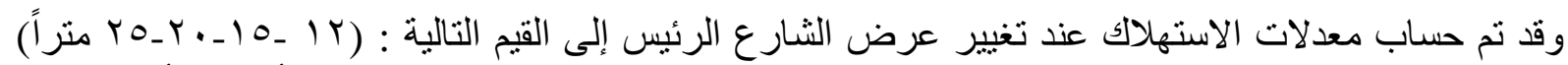

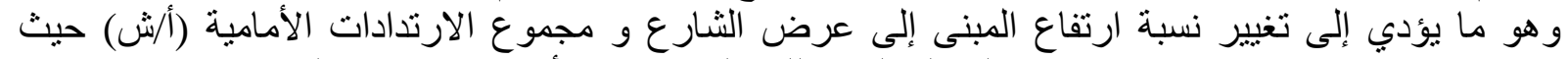

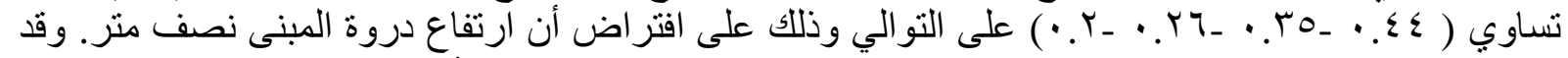

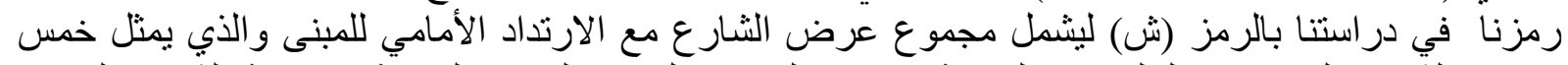

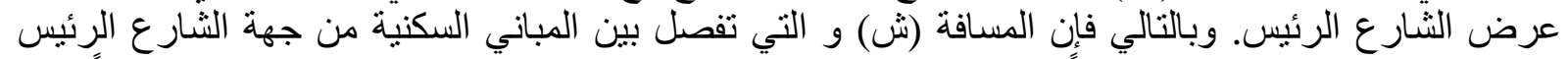

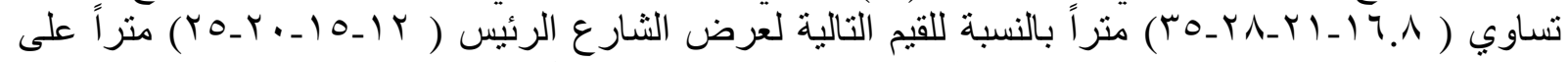

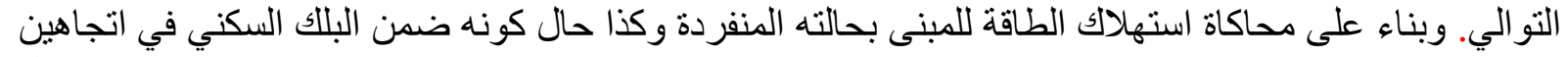

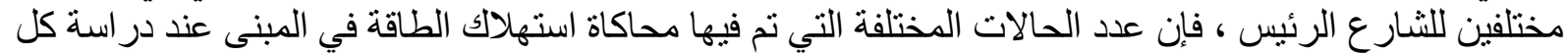
حالة من حالات النظام المطور للبناء بلغ · r حالة، أربع حالات تم فيها محاكاة استهلاك التطاقة في المبنى بحالته 
المنفردة في جميع الاتجاهات الرئيسة، وثمان حالات تم فيها محاكاة استهلاك الطاقة في المبنى بأربع اتجاهات

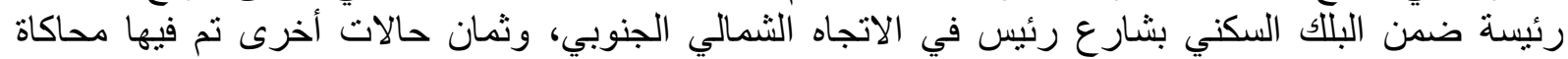

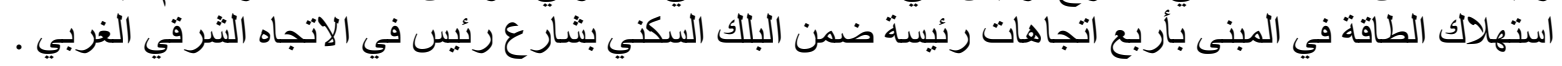

جدول 1. النسب المختلفة بين المباني ضمن البلك السكني

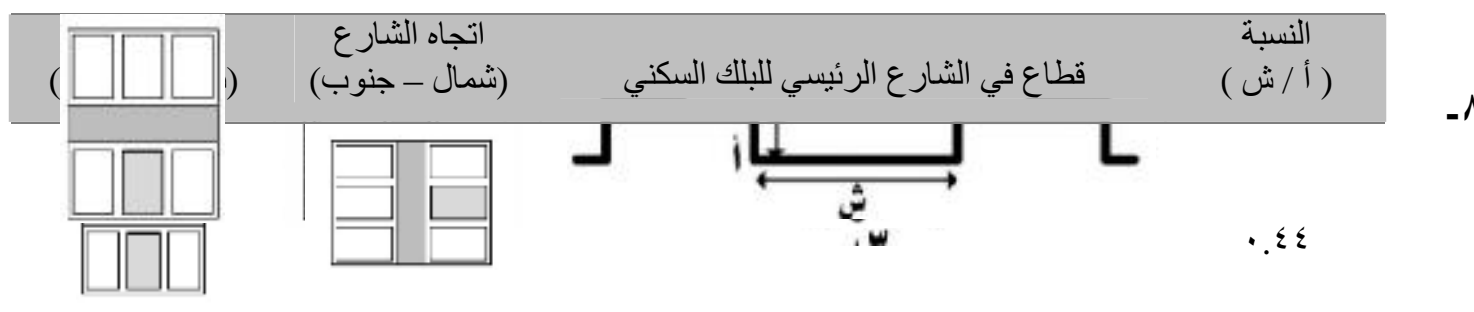

. ro

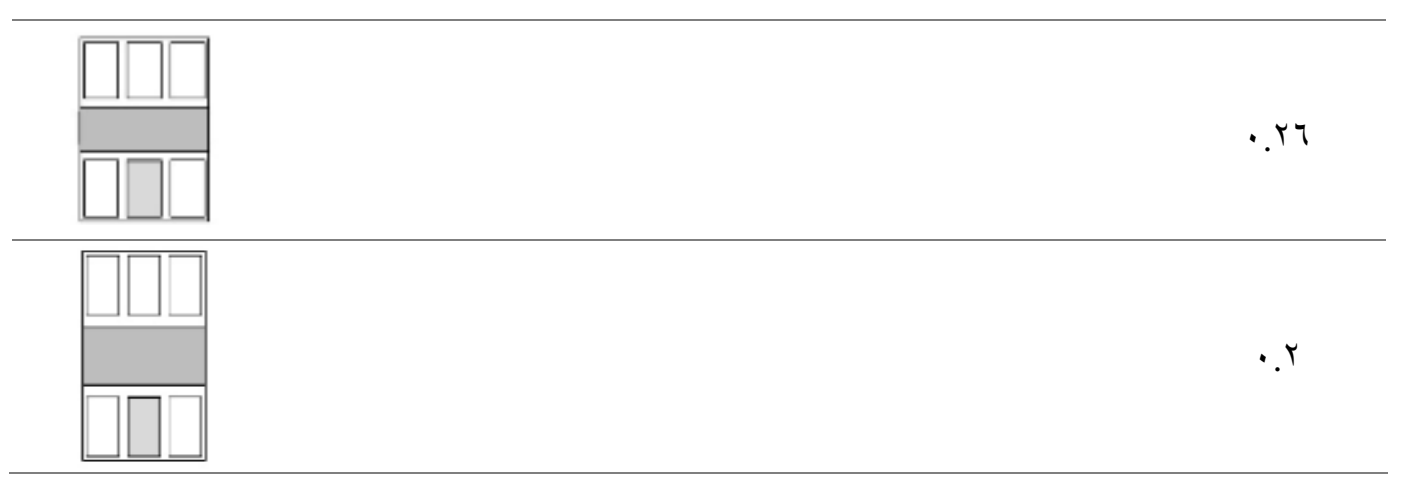

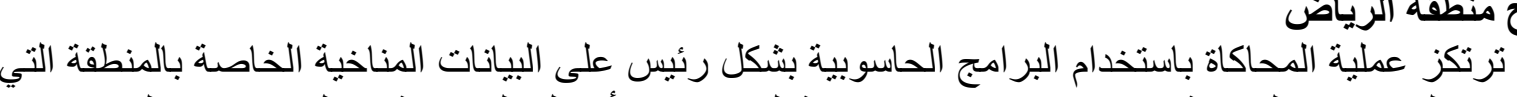

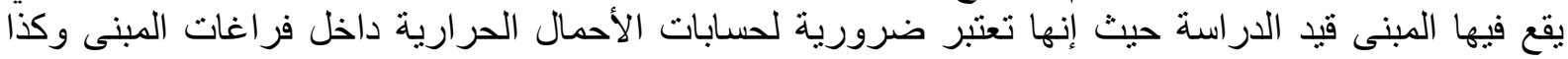

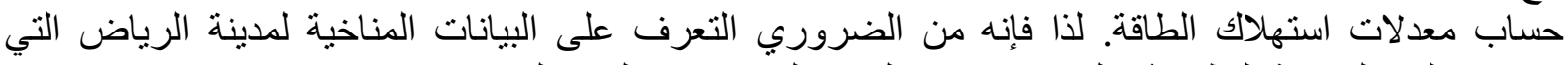

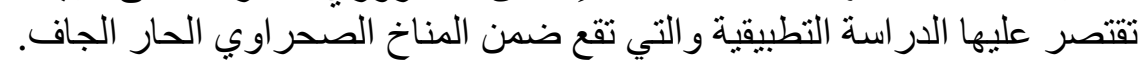
تقع مدينة الرياض في النصف الثمالي من الكرة الأرضية، في وسط شبه الجزيرة العربه العربية وفي وفي وسط منطقة

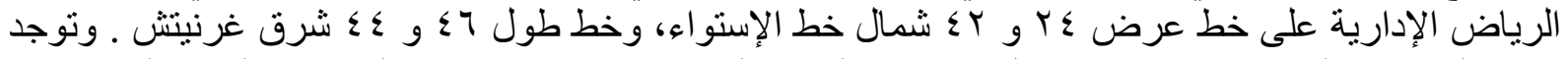

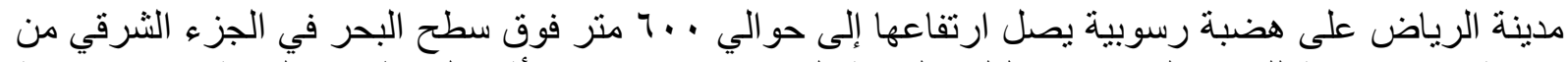

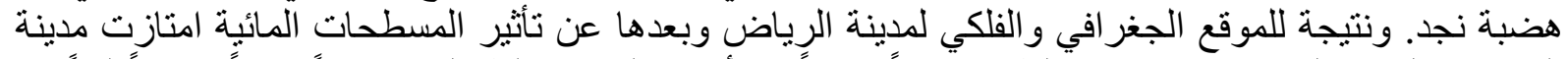

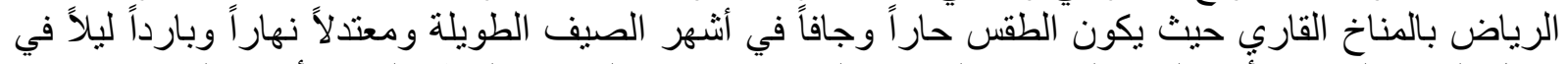

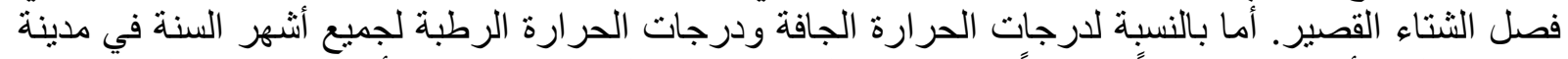

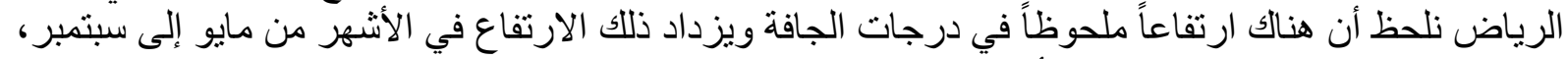

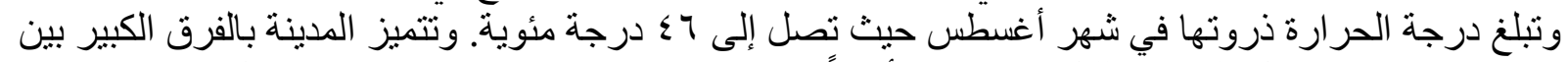

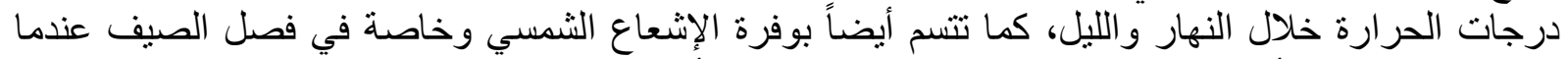

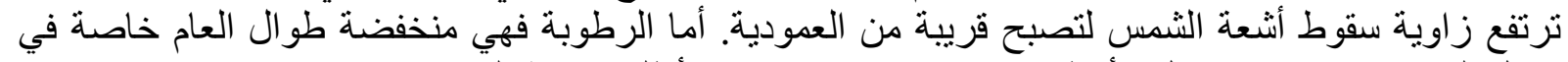

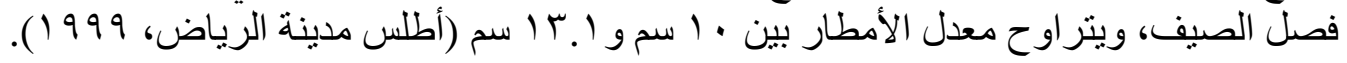




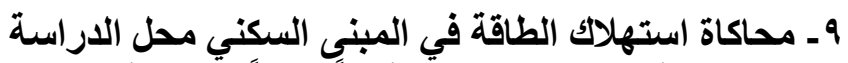

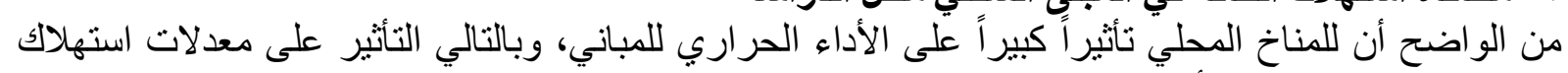

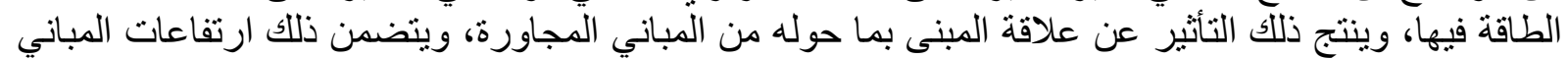

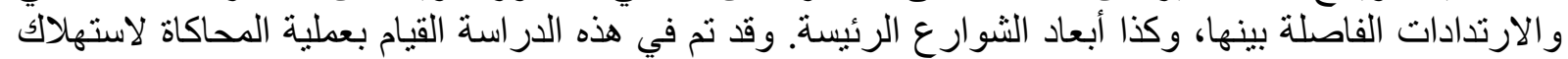

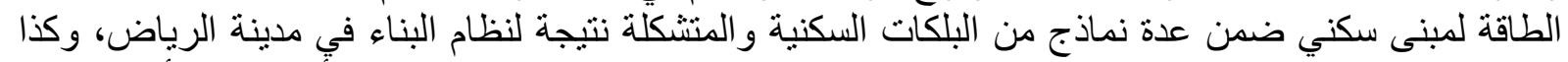

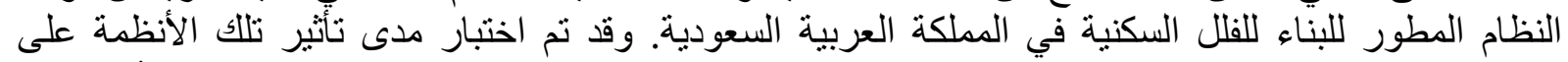

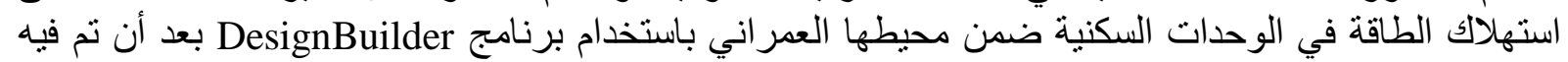

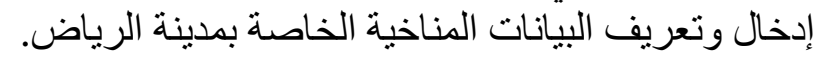

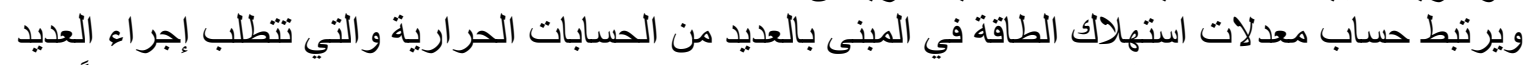

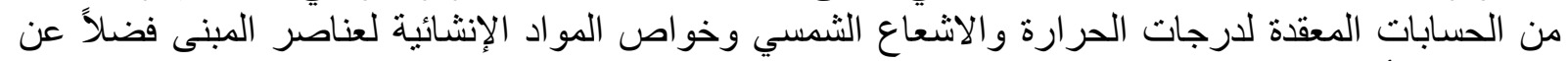

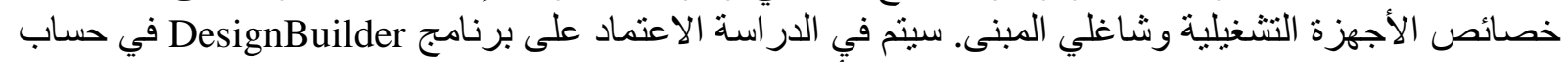

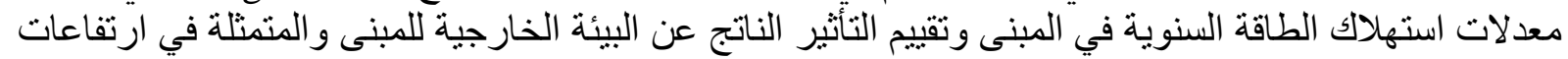

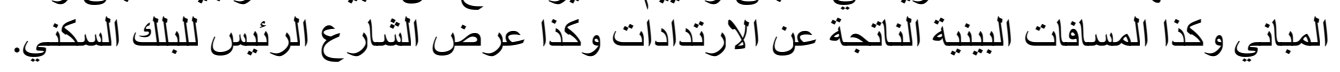

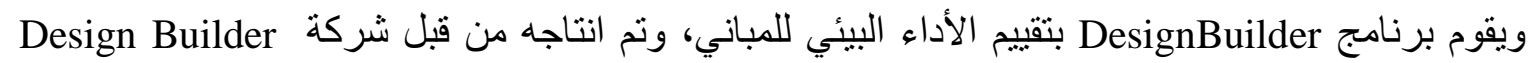

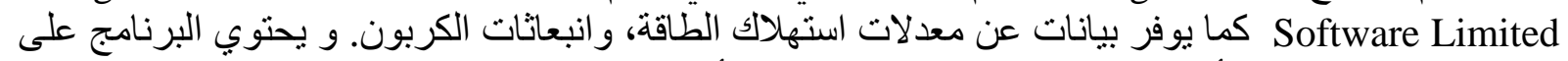

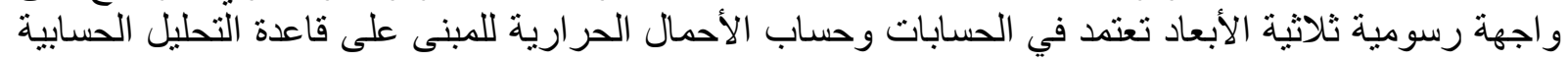

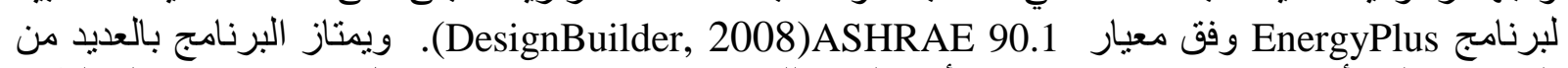

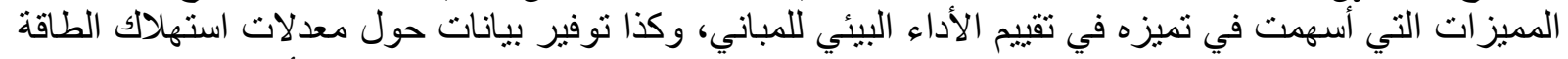

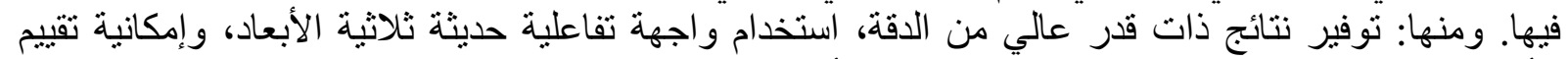

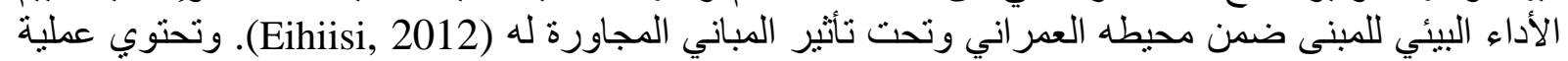

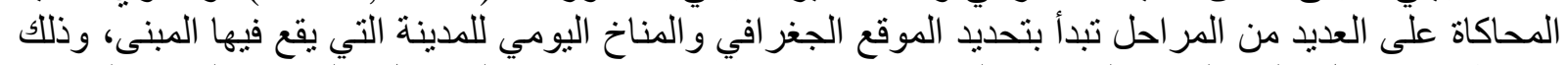

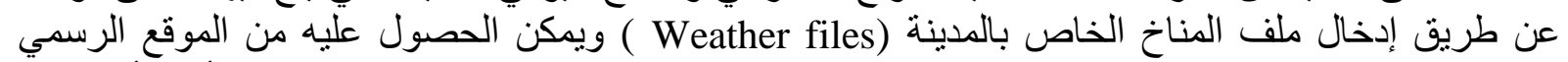

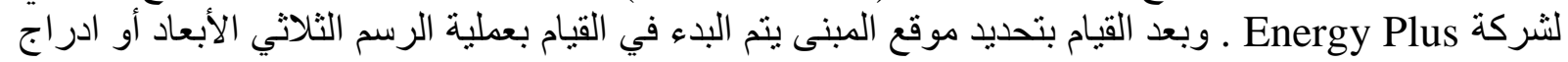

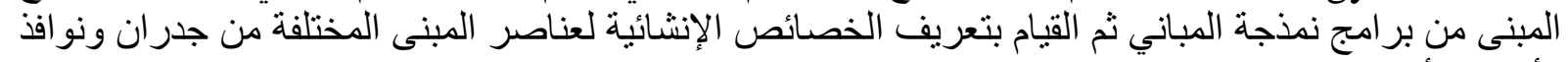
وأسقق وأرضيات (DesignBuilder, 2009).

\section{. 1 ـ نتائج تحليل البيانات}

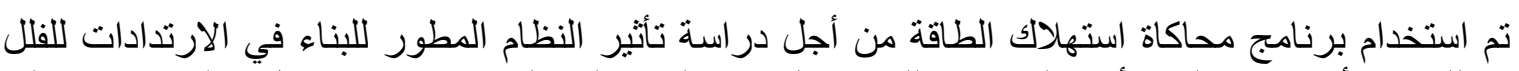

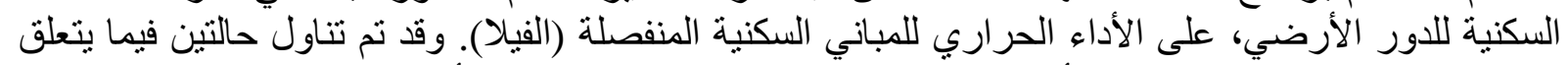

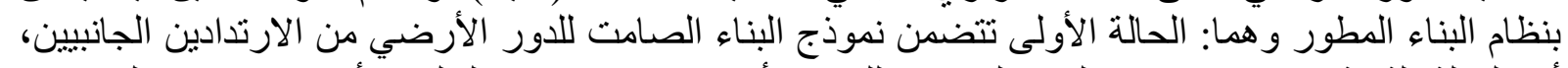

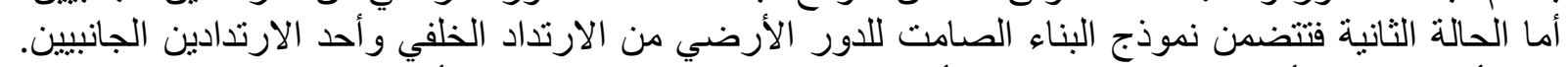

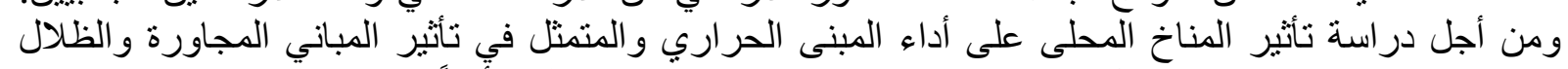

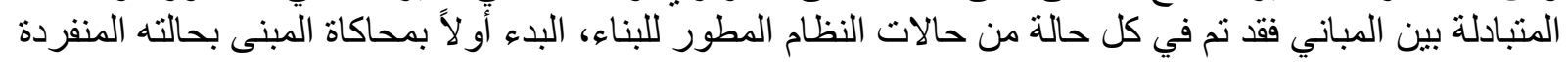

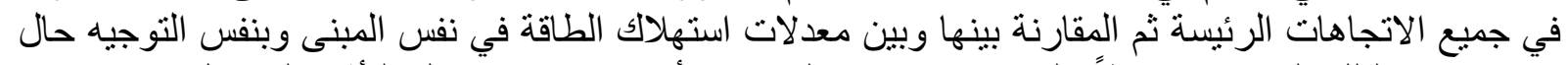

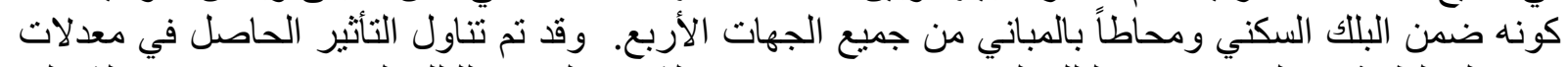

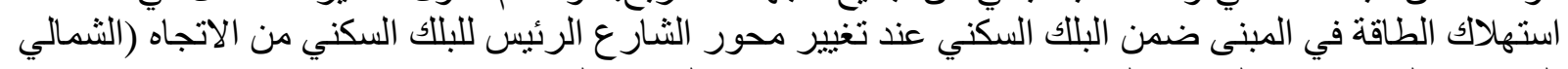
الجنوبي) إلى الاتجاه (الثرقي الغربي) وكذا عند تغيير عرض الثير الثارع الرئيسي. 


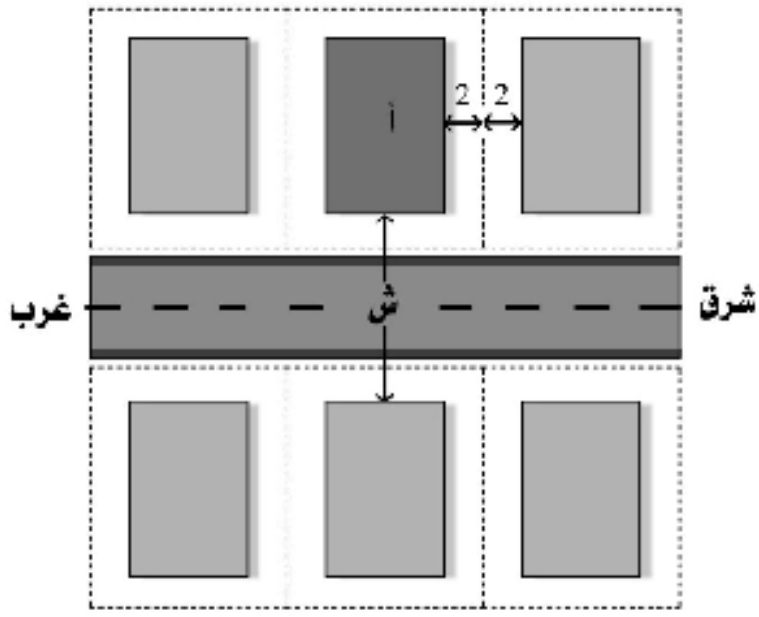

شكل ؛ ـ رسم توضيحي يوضح الأبعاد المكانية بين المباني ضمن البلك السكني

ـ 1 ـ تقييم تأثير نموذج البناء الصامت للاور الأرضي من الارتدادين الجانبيين (الحالة الاولى)

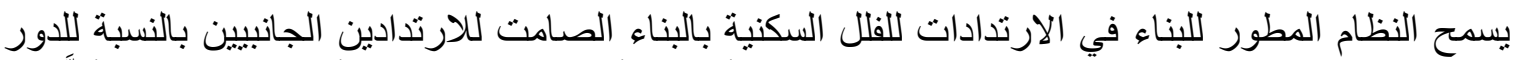

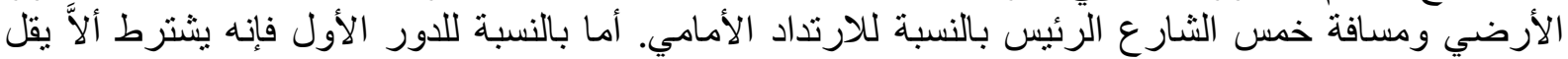

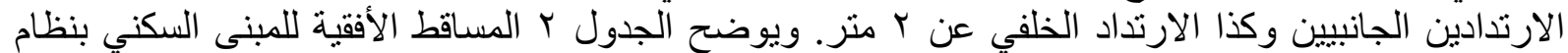

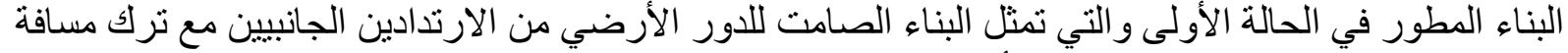

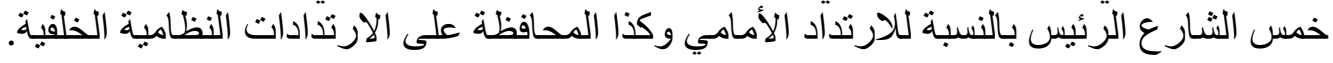

جدول ז. المساقط الأفقية للمبنى السكني بنظام البناء المطور - البناء الصامت للاور الأرضي من الارتدادين الجانبيين

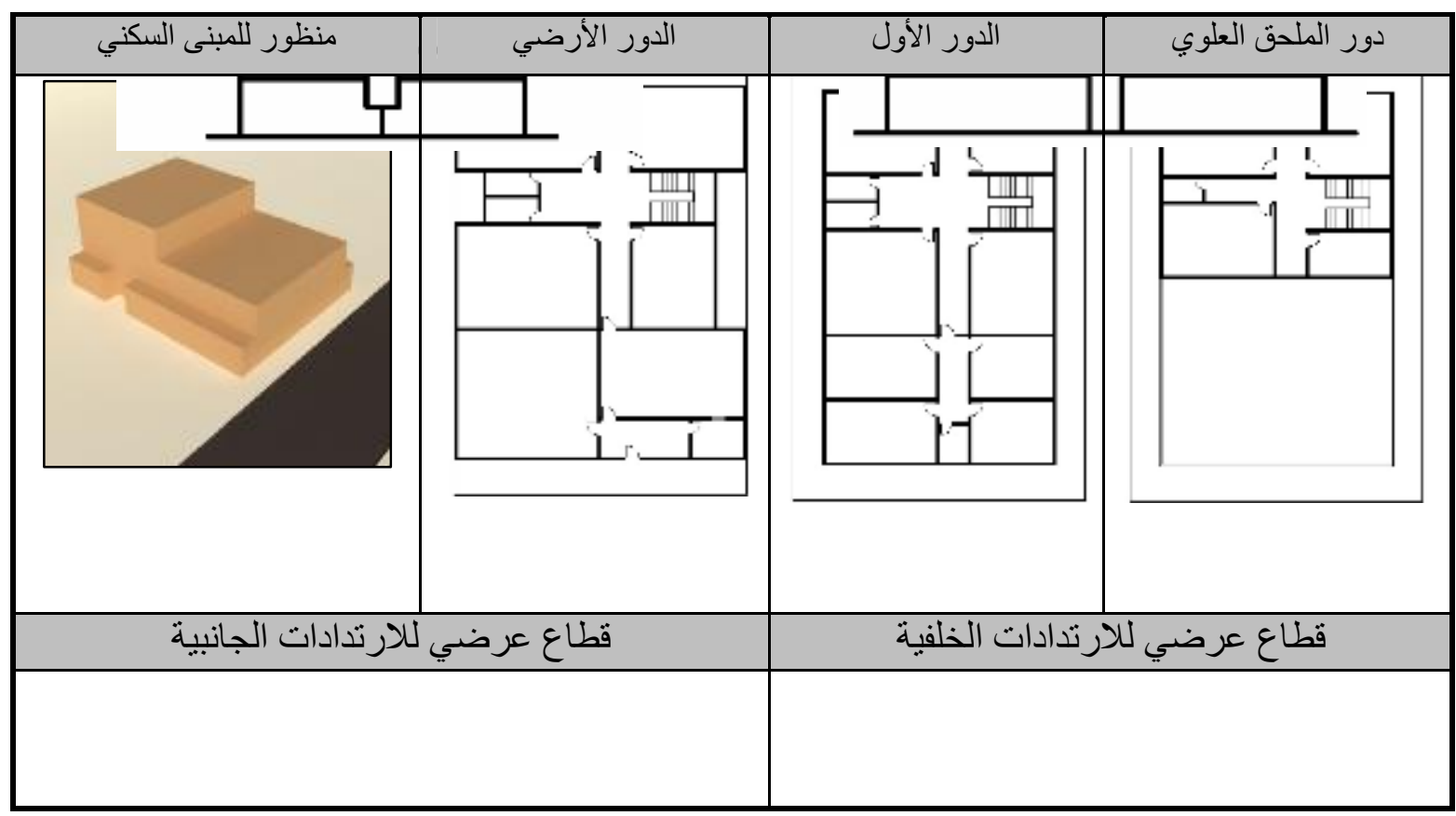

وقد تم في البداية إجراء محاكاة لاستهلاك الطاقة في المبنى بحالته المنفردة وذللك في جميع الاتجاهات

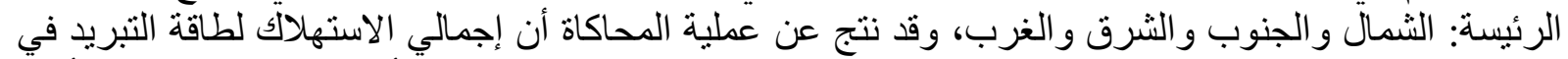

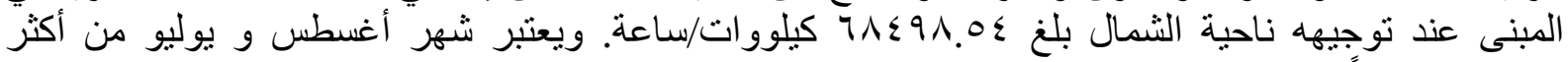

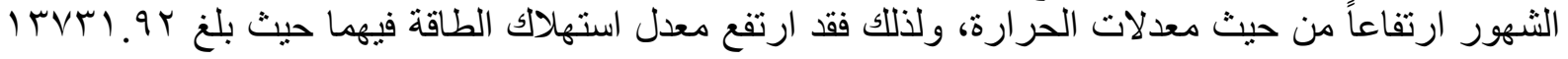




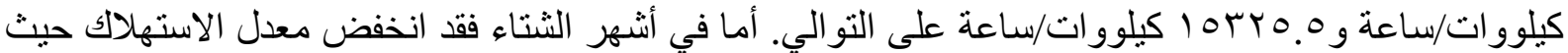

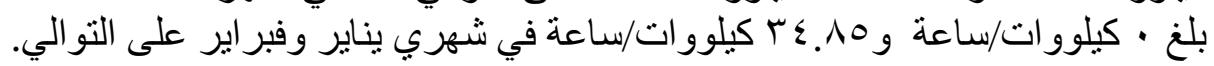

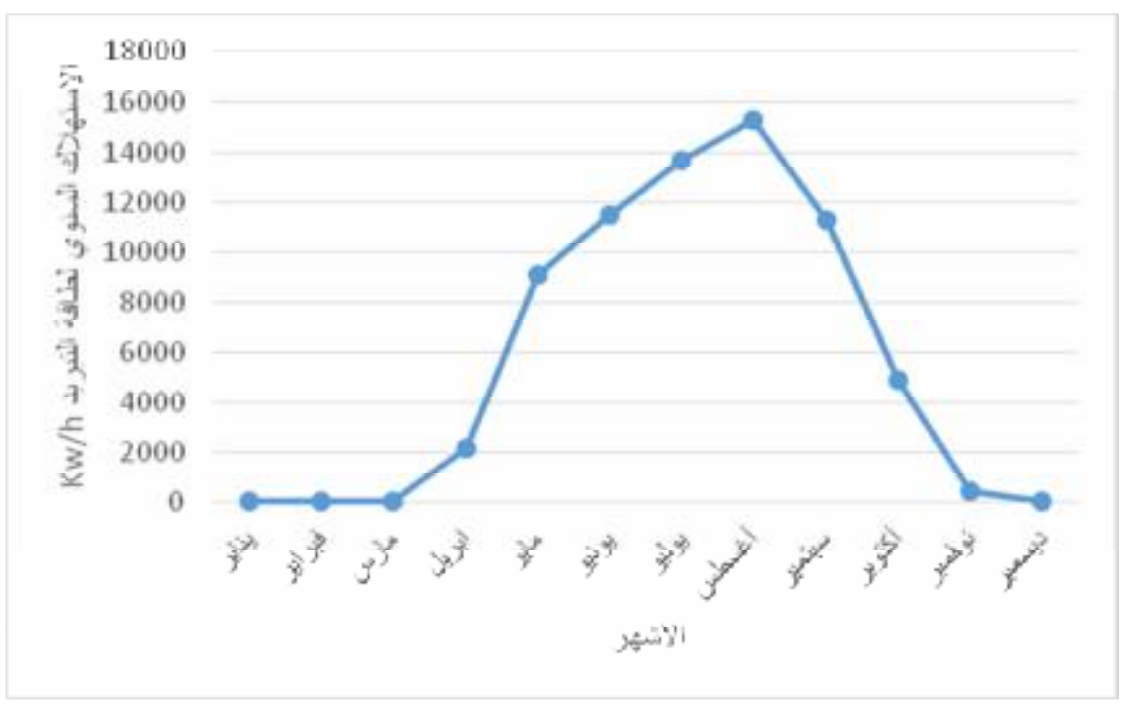

شكل •. الاستهلاك السنوي لطاقة التبريد في المبنى السكني بواجهة شمالية في حالته المنفردة ـ النظام

أما بالنسبة لمعدل استهلاك الطاقة للمبنى بحالته المنفردة عندما يتم توجيهه ناحية الغرب، فقات بلغ معدل

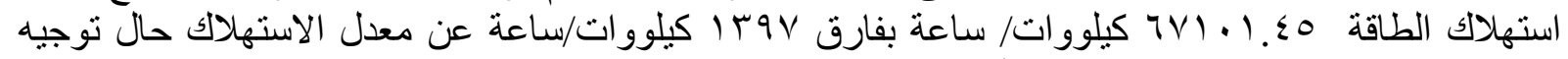

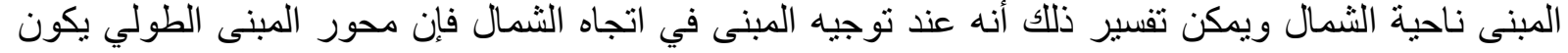

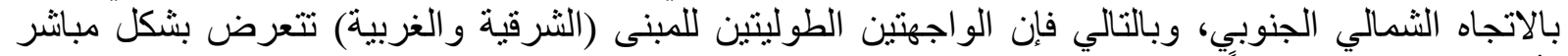

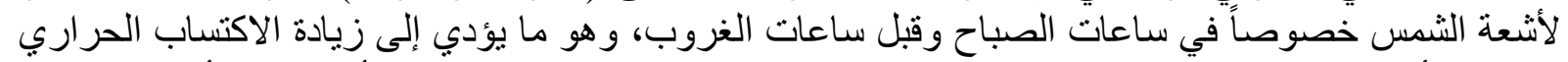

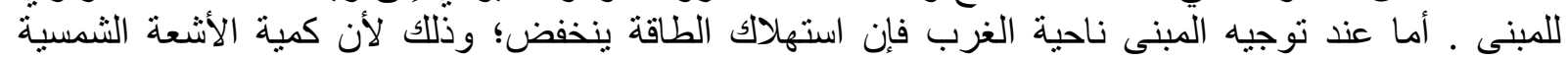
المسلطة على الواجهتين الثمالية والجنوبية تعتبر منخفضة مقارنة بالأشعة المسلطة على الواجهنين الثرقية و الغربية.

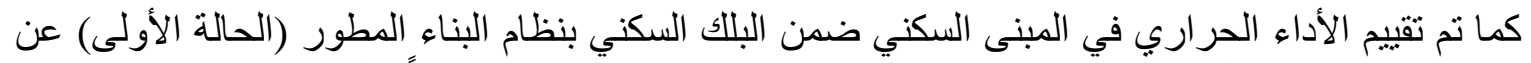

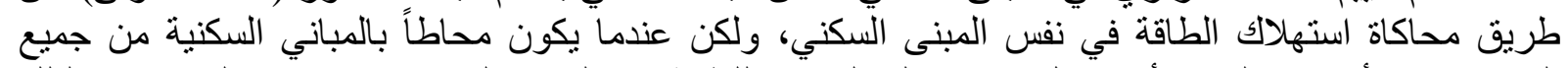

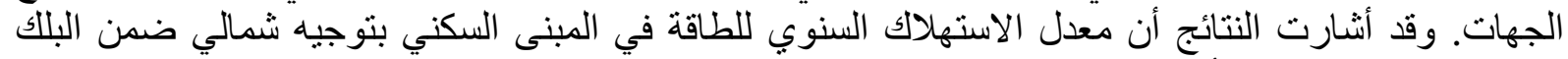

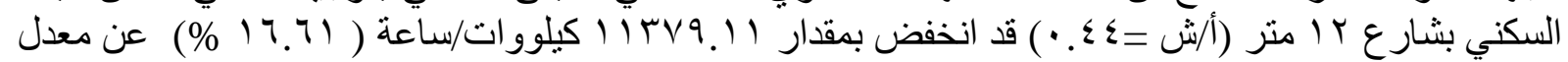

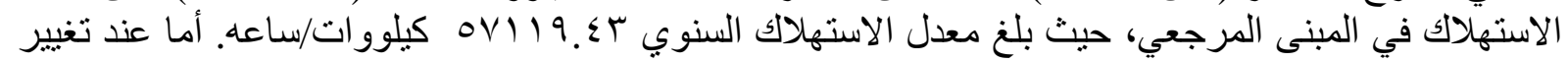

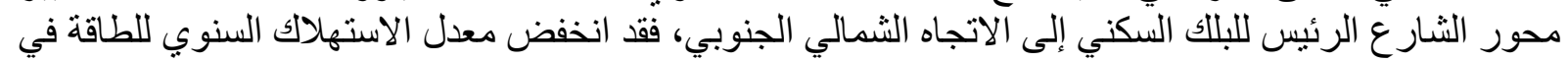

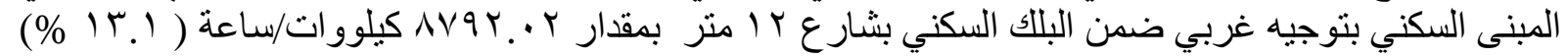

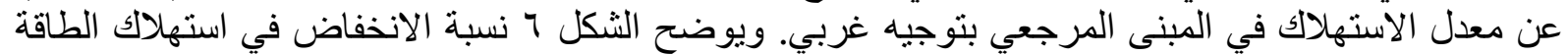
في المبنى السكني ضمن البلك السكني مقارنة بمعدل الاستهلاك للمبنى بحالته المنفردة. 


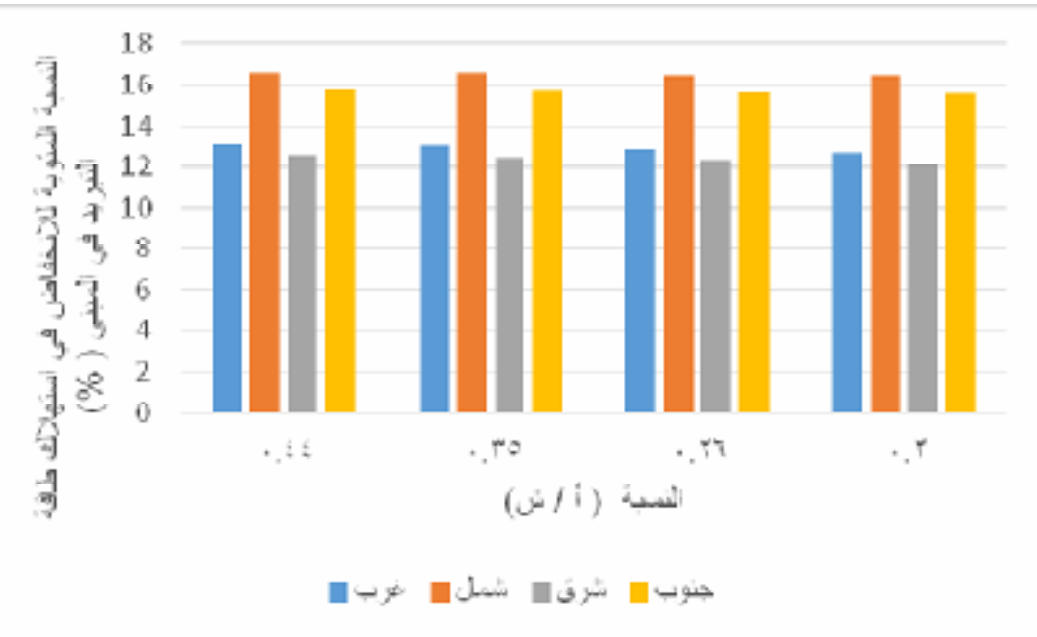

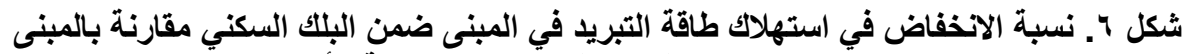

بحالته المنفردة - النظام المطور للبناء ( الحالة الأولى)

ويعتبر الاكتساب الحراري للمبنى والناتج عن أثعة الثمس المباشرة من أهم العو امل التي تؤدي إلى زيادة

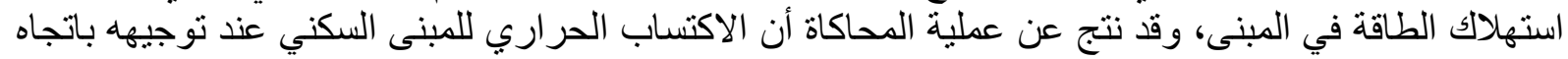

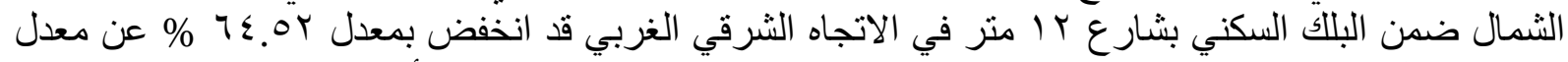

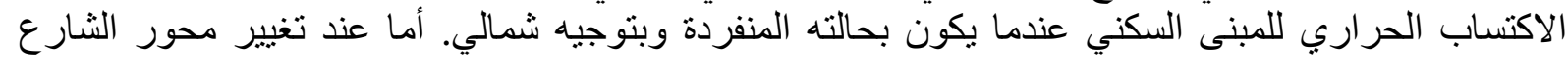

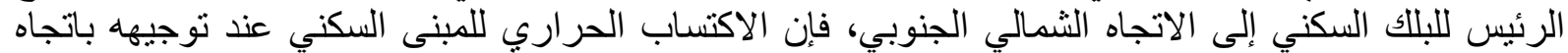

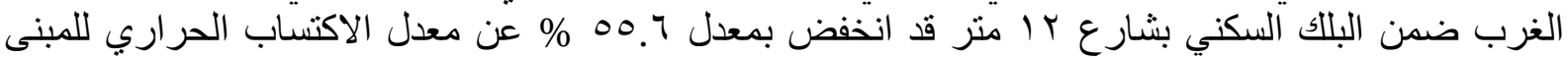

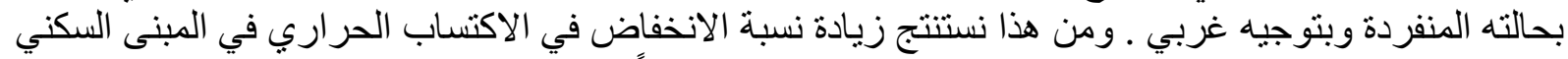

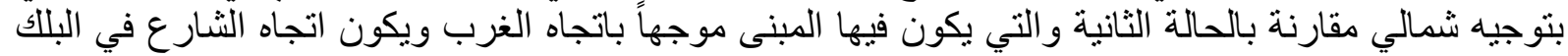

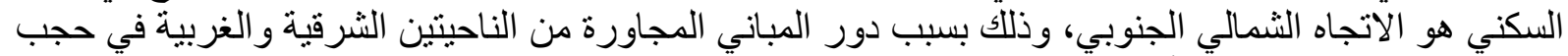

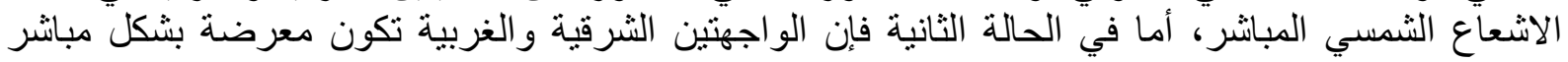

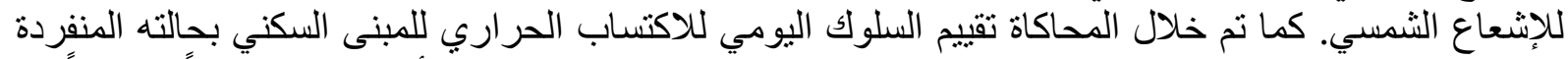

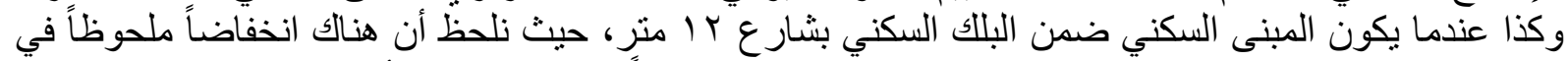

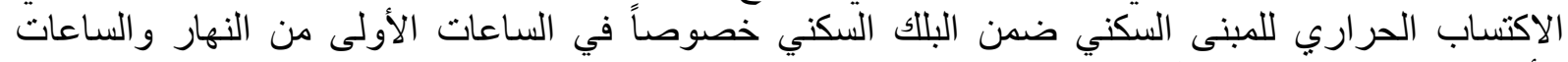

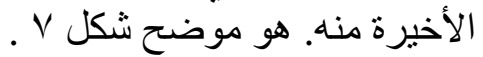

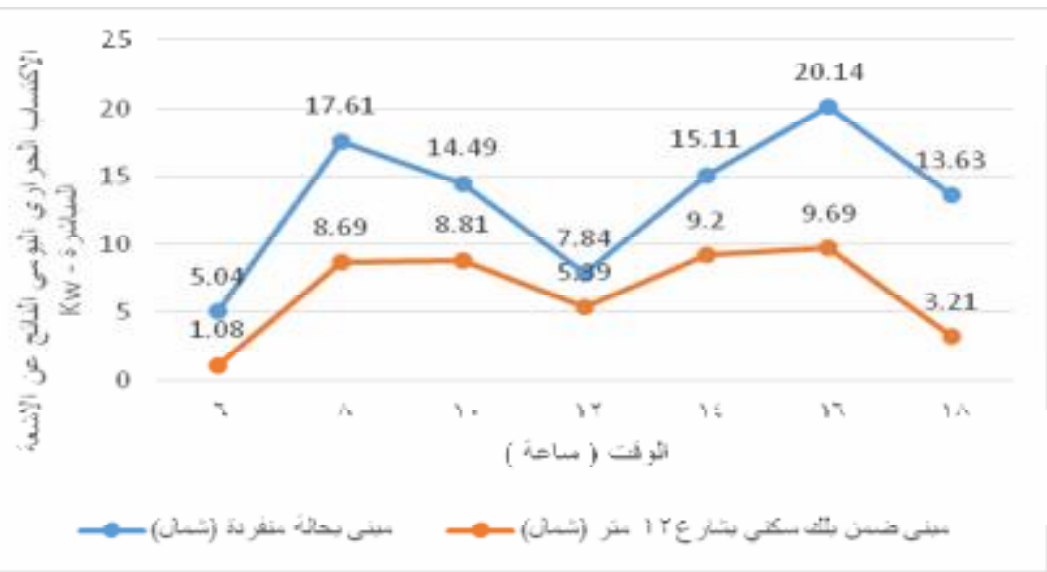

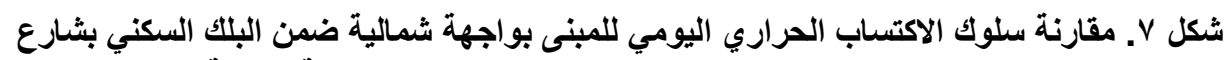

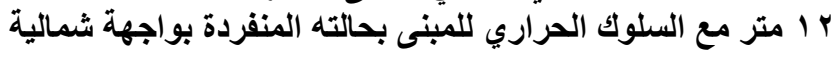


• ـ ـ تقييم تأثير نموذج البناء الصامت للاور الأرضي من الارتدادين الجانبي و الخلفي (الحالة الثانية)

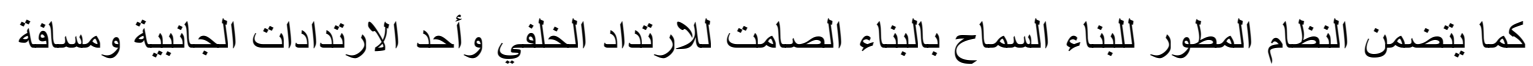

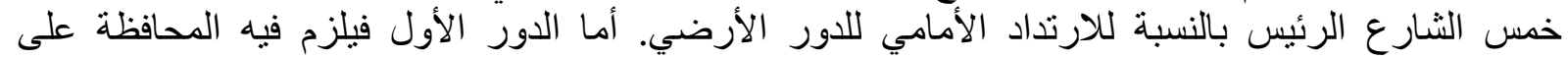

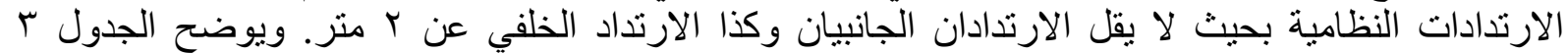

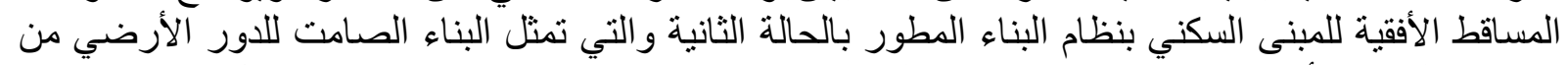

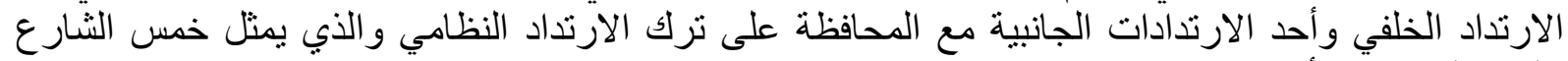
بالنسبة للارتداد الأمامي. جدول س. المساقط الأفقية للمبنى السكني بنظام البناء المطور ـ البناء الصامت للادور

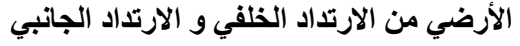

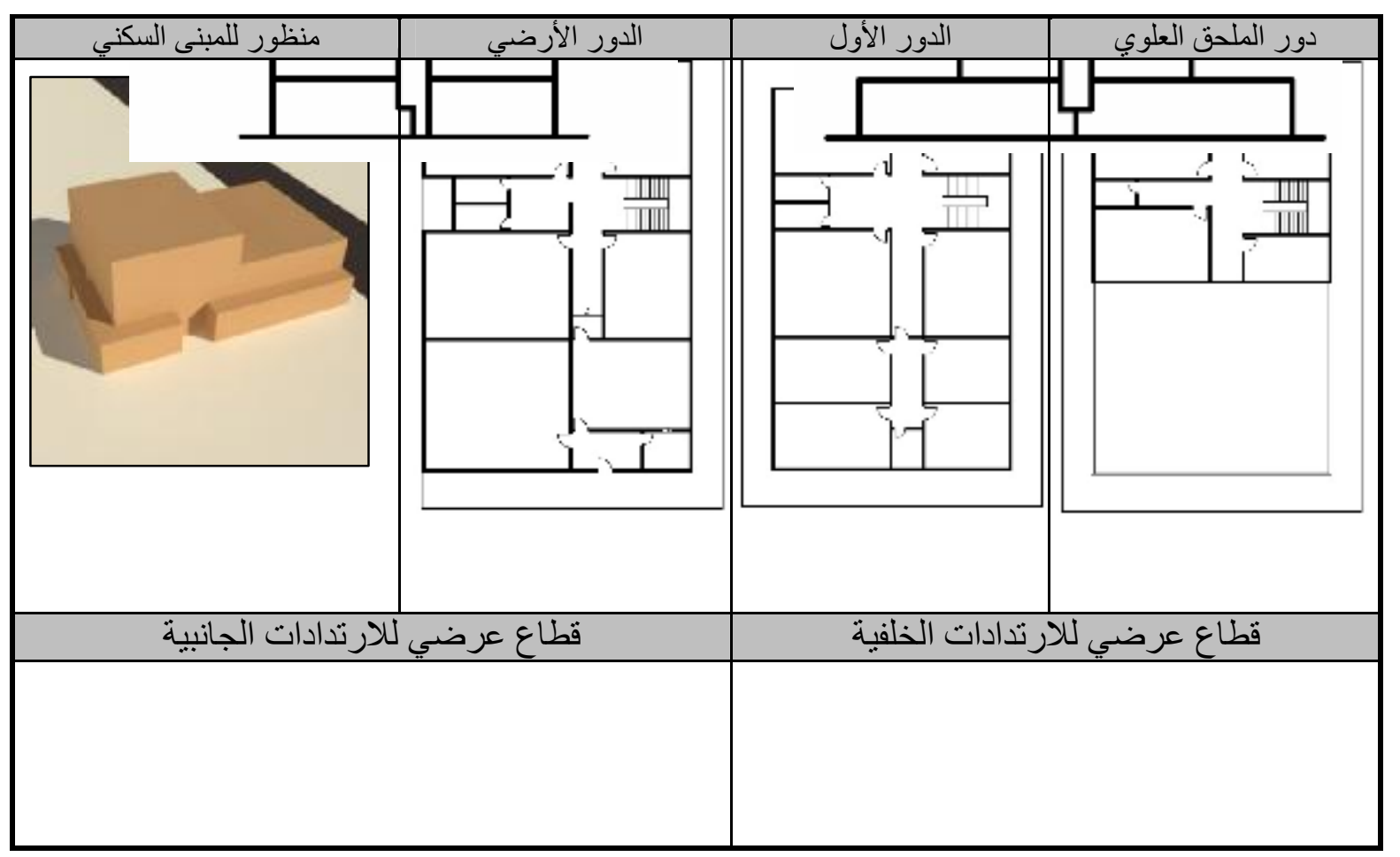

وقد نتج من عملية محاكاة استهلاك الطاقة أن إجمالي الاستهلاك لطاقة التبريد في المبنى بحالته المنفردة عند الماند

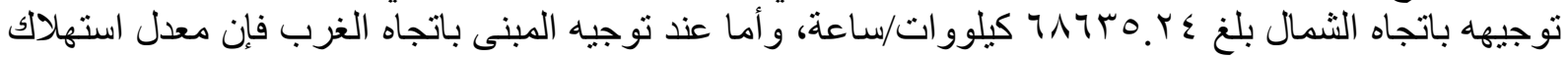

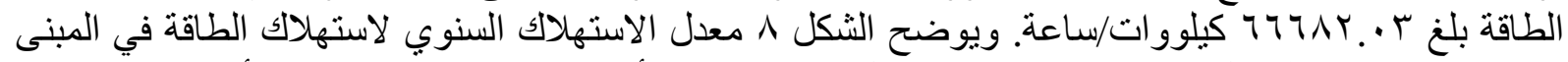

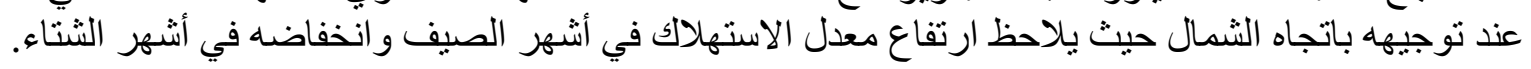




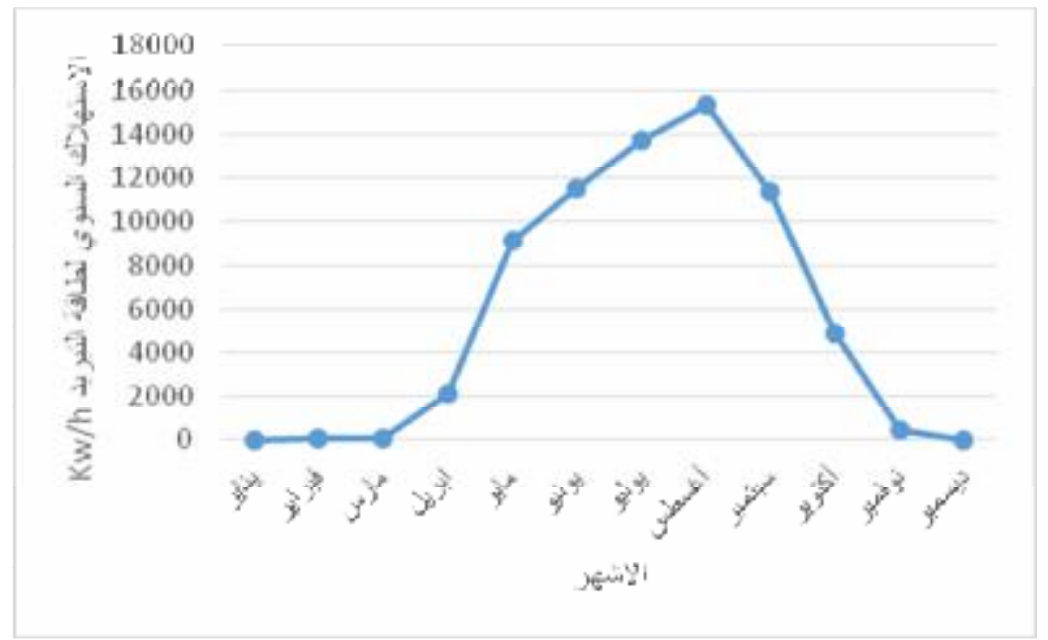

شكل ^ـ الاستهلاك السنوي لطاقة التبريد في المبنى السكني بواجهة شمالية في حالته المنفردة ـ النظام المطور للبناء ( الحالة الثانية)

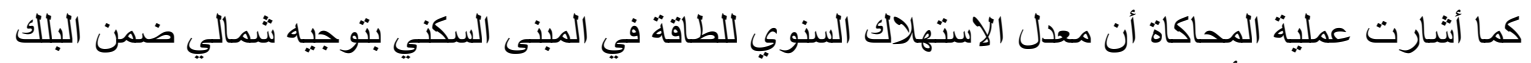

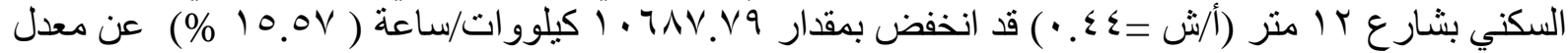
الاستهلاك في المبنى المرجعي، حيث بلغ معدل الاستهلاك السنوي 0.

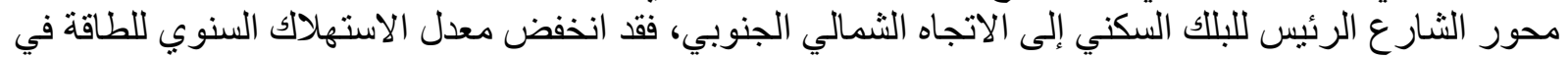

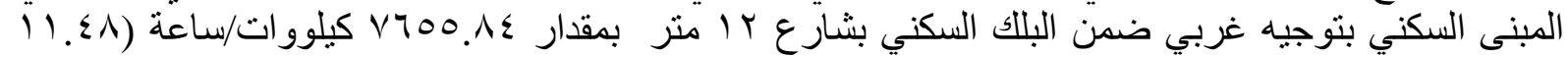
\%) عن المبنى المرجعي. ويوضح الثكل 9 نسبة الانخفاض في استهلاك الطاقة في المبنى السكني ضمن البلك الكانك السكني مقارنة بمعدل الاستهلاك للمبنى بحالته المنفردة.

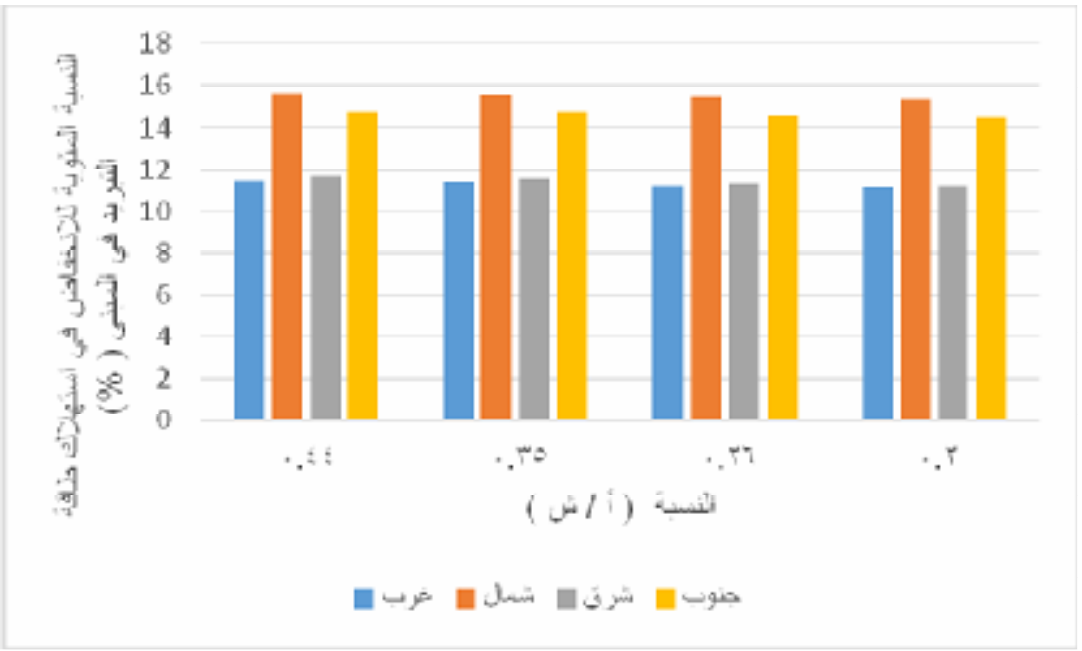

شكل 9.

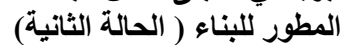

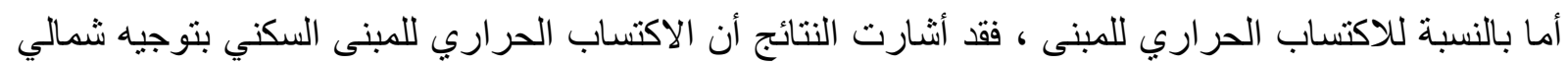

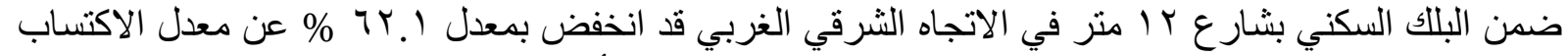

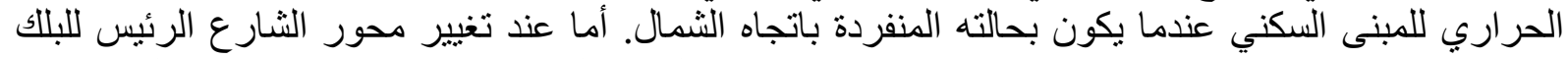

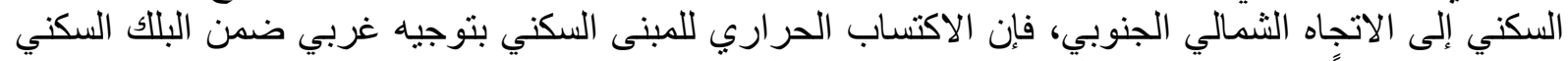

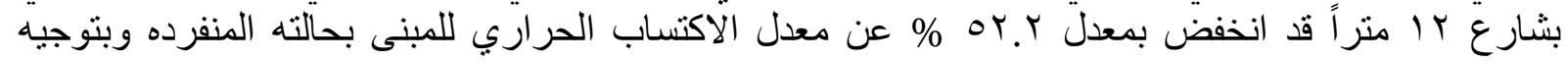


غربي. ويوضح الثكل • ا مقارنة بين السلوك اليومي للاكتساب الحراري خلال ساعات النهار للمبنى السكني

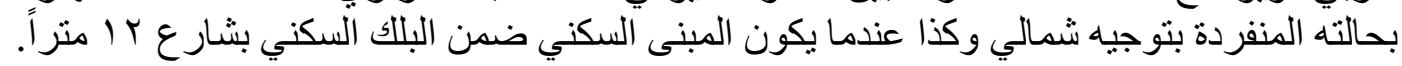

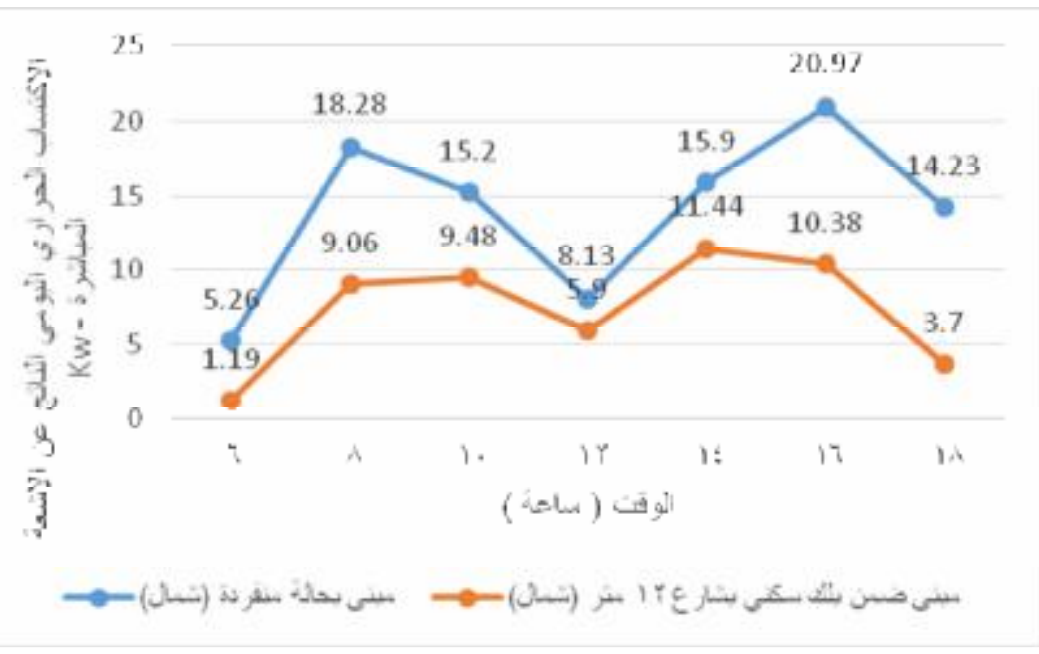

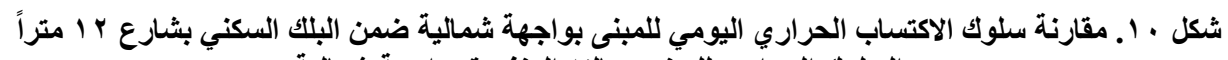
مع السلوك الحراري للمبنى بحالته المنفردة بواجهة شمالية المالية

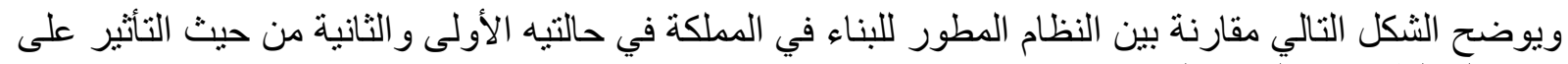

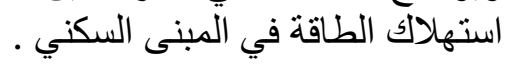

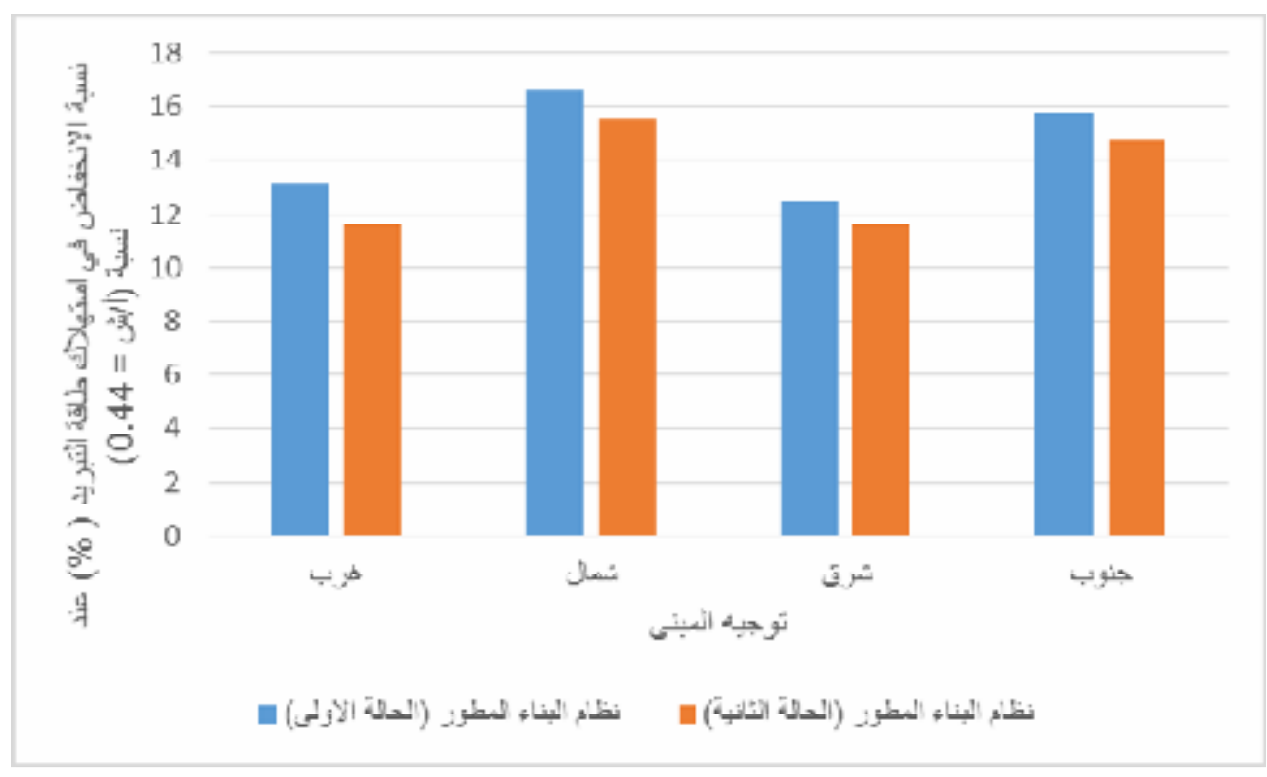

شكل 11. نسبة الانخفاض في استهلاك طاقة التبريد في المبنى ضمن البلك السكني بنسبة (أشش= ؛ ؛ . · ) في النظام المطور للبناء (الحالتين الأولى و الثانية)

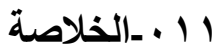

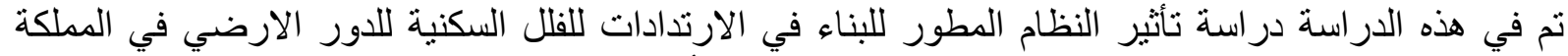

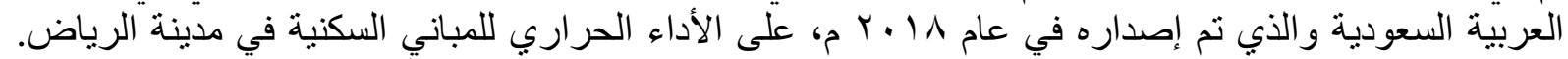

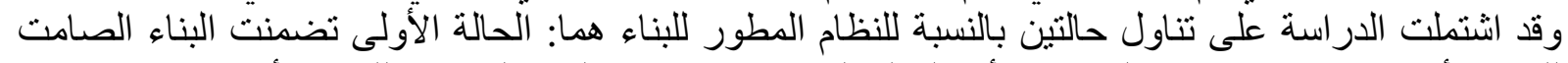

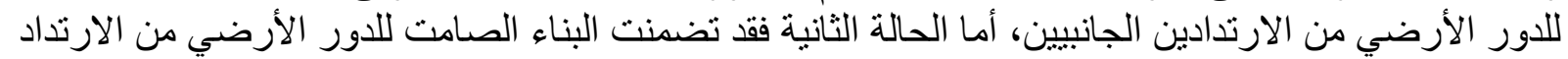

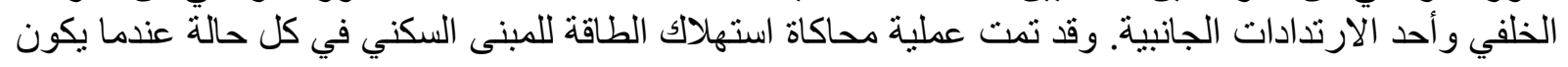


المبنى بحالته المنفردة ثم مقارنة ذلك بالأداء الحراري للمبنى عندما يكون ضمن البلك الكاد السكني محاطاً بالمباني

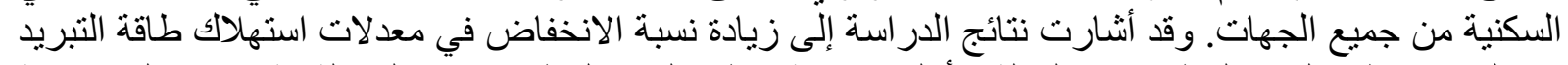

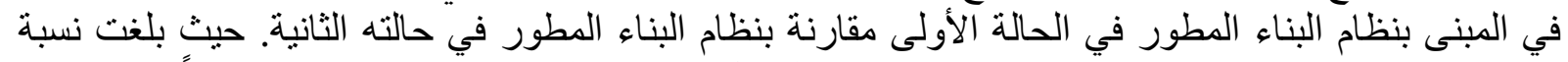

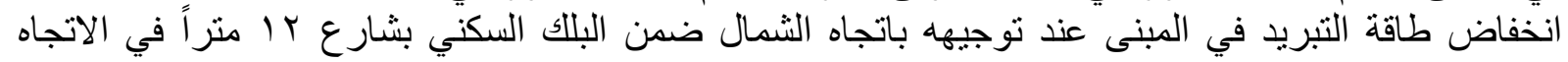

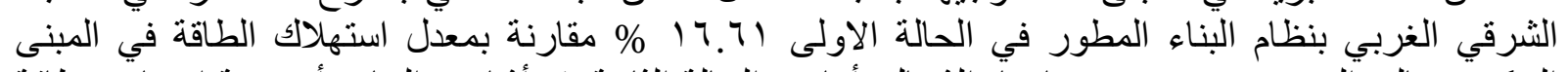

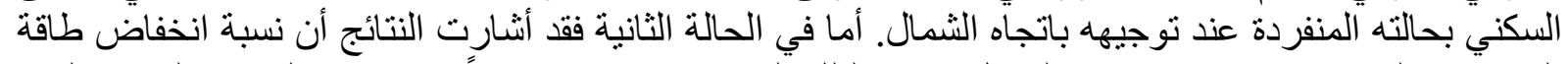

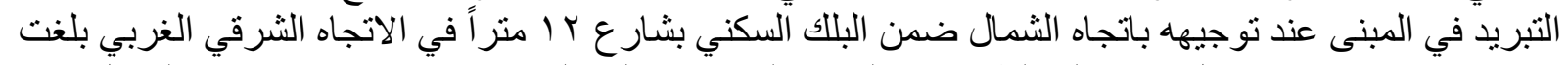

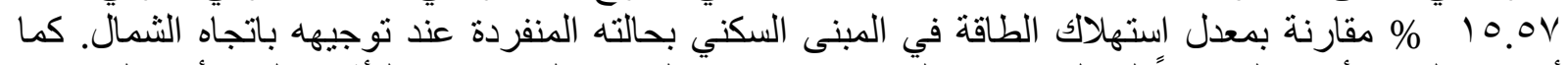

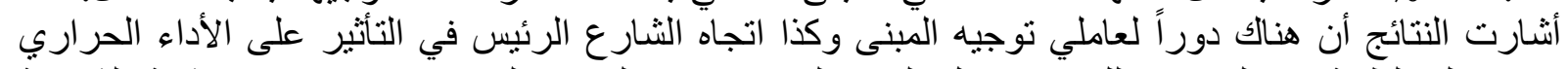

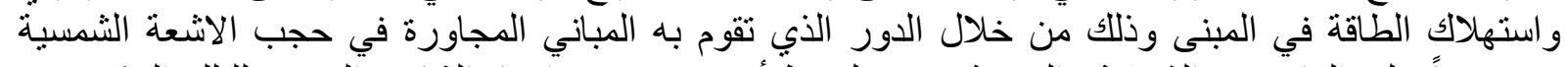

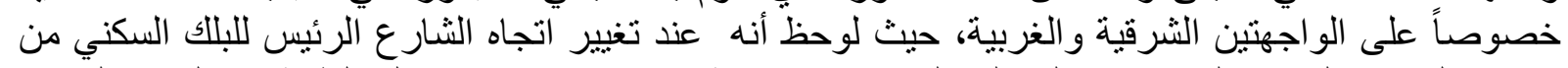

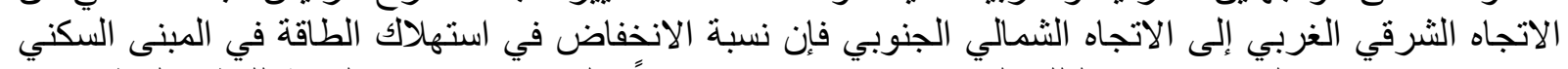

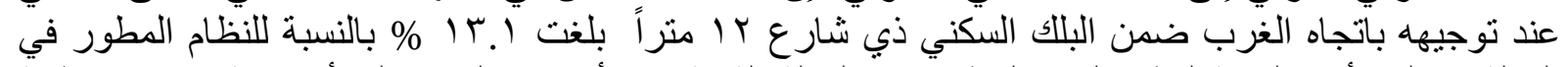

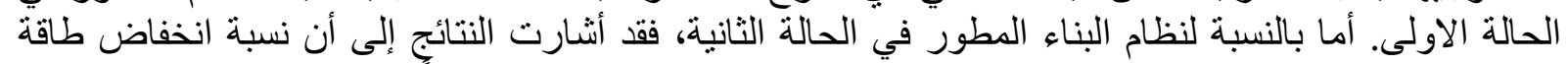

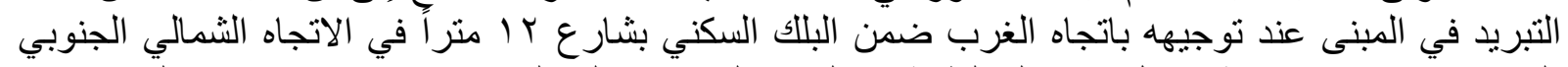

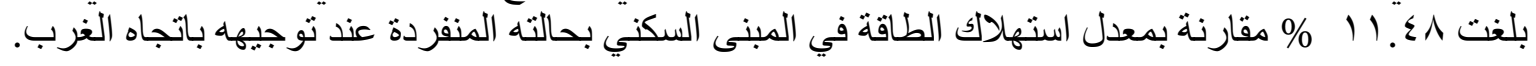

- ـ ـ التوصيات البحث بإدر اج محددات التصميم البيئي والتي تتو افق مع الظروف المناخية المحلية للمنطقة ضمن

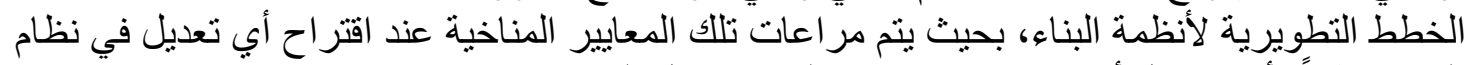

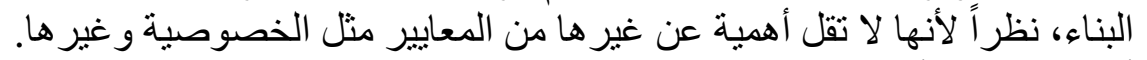

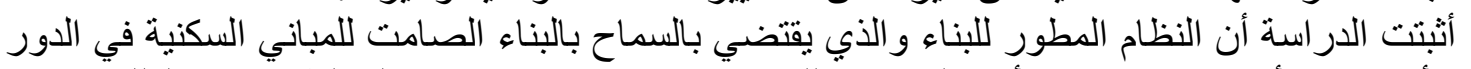

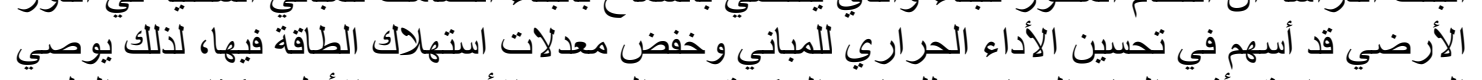

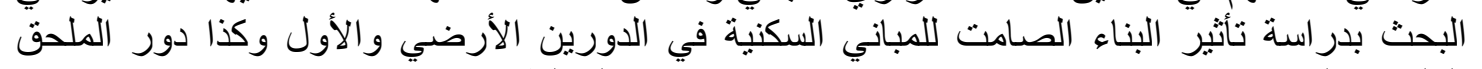

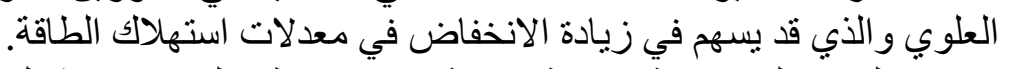

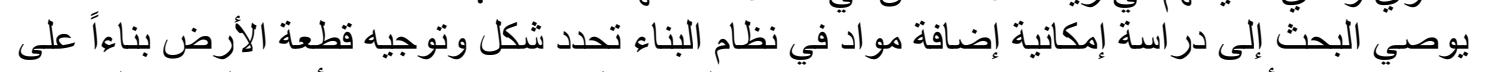

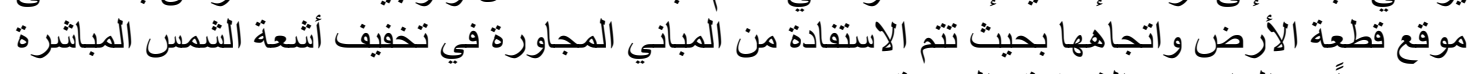

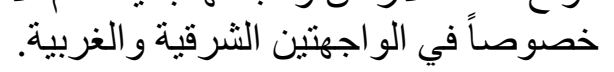
هذه الورم الباحثنان بالثكر وتقدير والعرفان لجامعة الملك سعود ممثلة في مركز البحوث في كلية العمارة والتخطيط، على دعم

ا. أطلس مدينة الرياض (999 (199)، إعداد لجنة أطلس منطقة الرياض، قسم الجغر افيا، كلية الآداب، جامعة

\section{المراجع العربية}

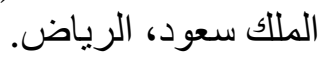

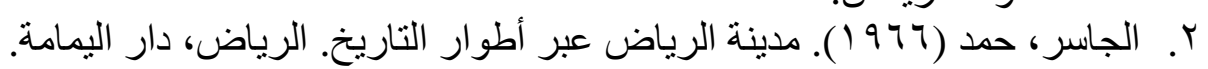

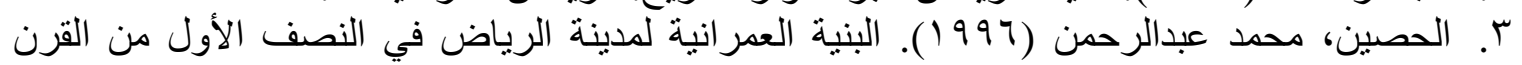

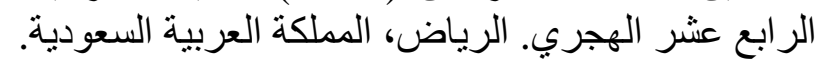

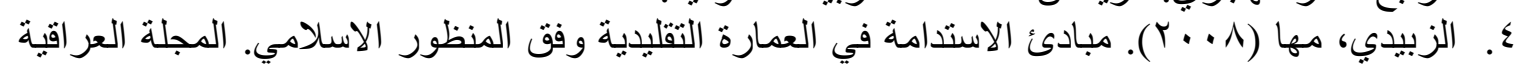

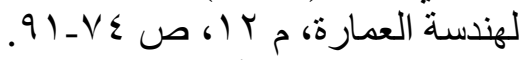

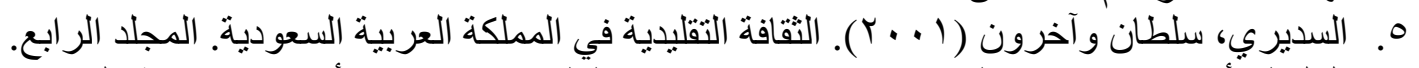

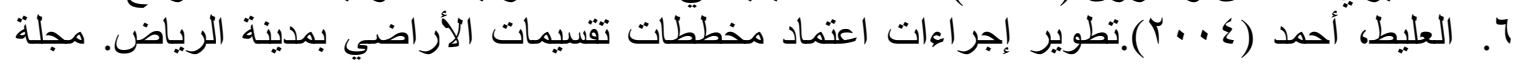

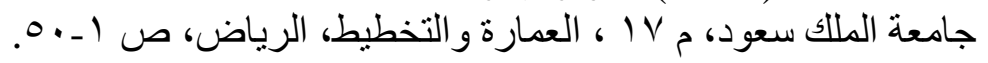




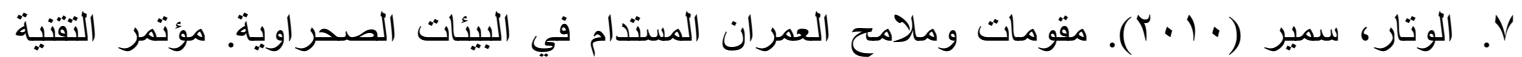

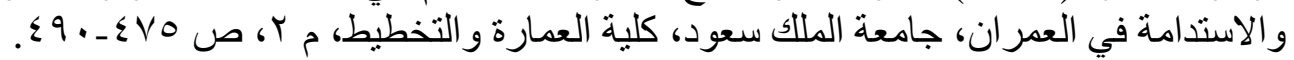

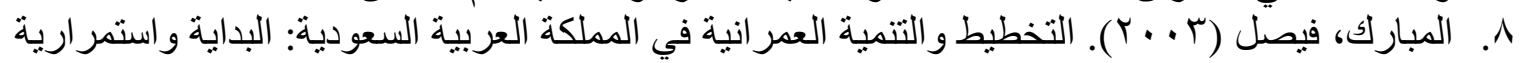

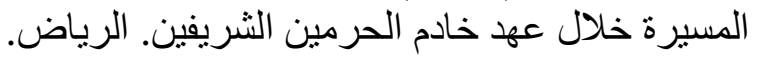

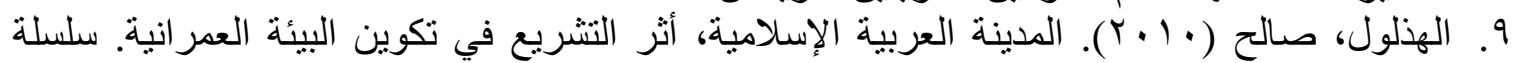
علوم العدران.

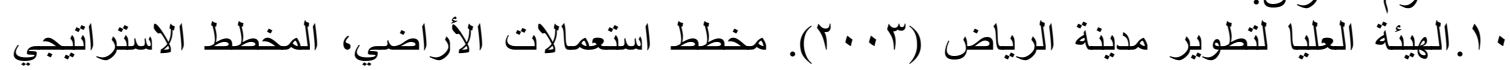

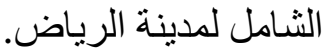

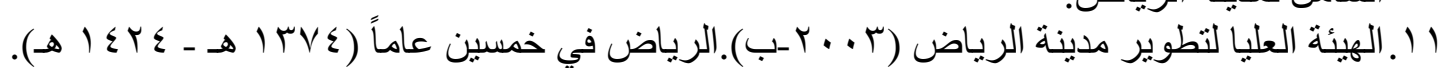

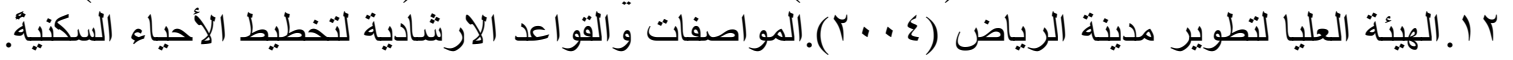

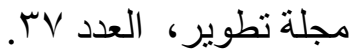

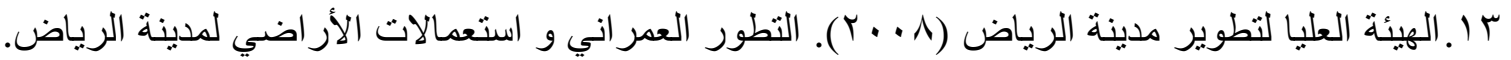

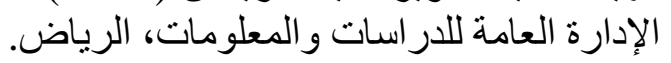

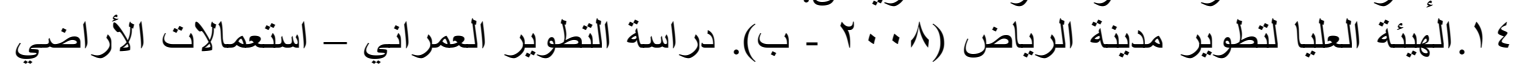

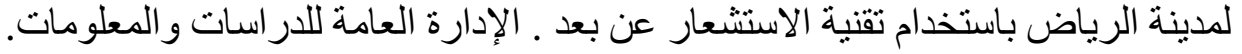

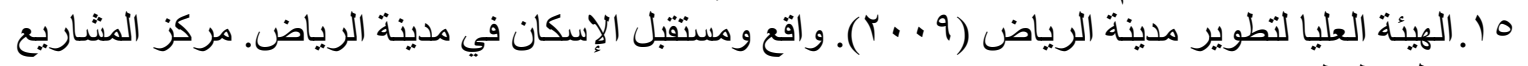
و التخطيط.

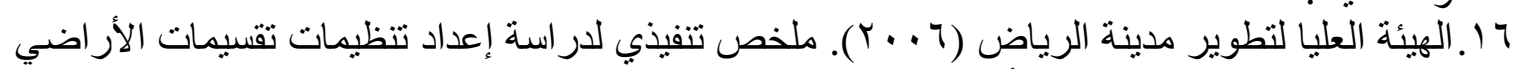

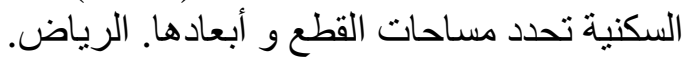

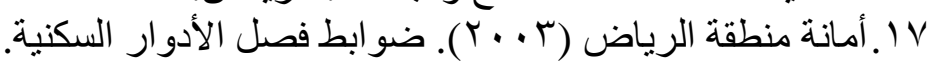

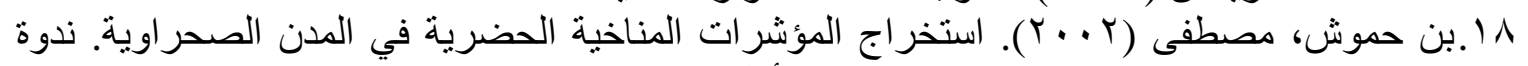

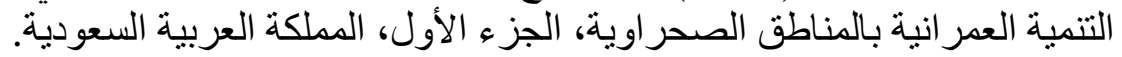

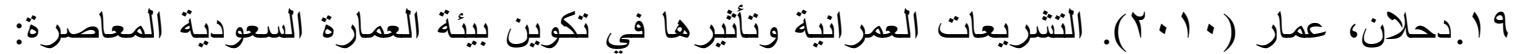

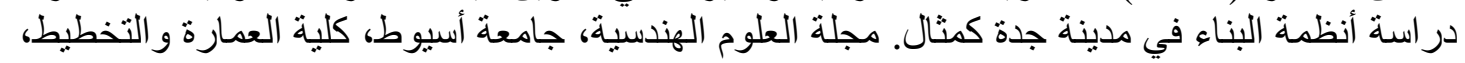

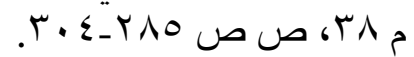

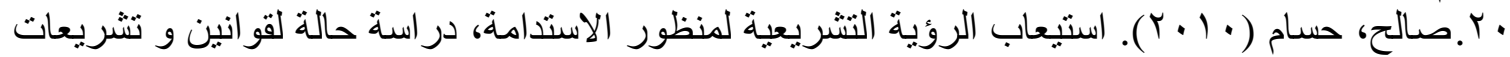

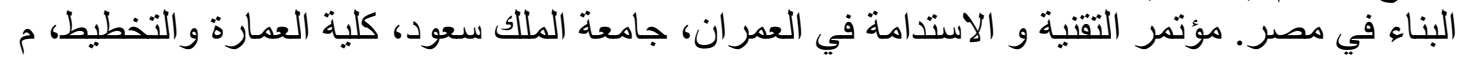

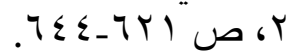

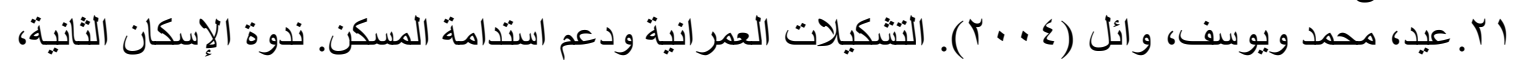

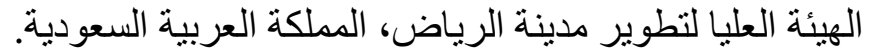

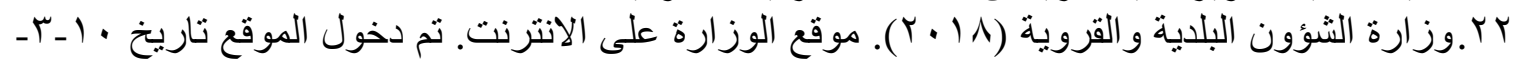
. Y. 19

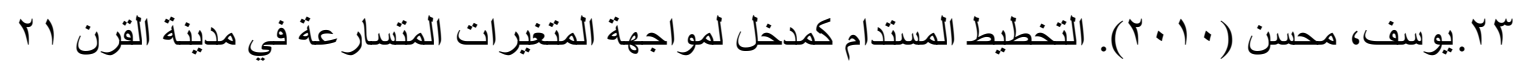
- حالة در اسية مدينة الرياض. مؤتمر التقنية والاستدامة في العمر ان، جامعة الملك سعود، كلية العمارة

\section{REFERENCES}

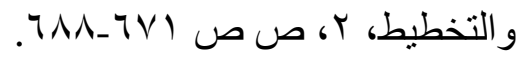

1. Al-Hemeddi, N., AlSaud, K., (2001). The Effect of a Ventilated Interior Courtyard on the Thermal Performance of a House in a Hot-arid Region. Journal of Renewable Energy, Vol. 24: 581-595.

2. Alshehri, A. and Belloumi, M., (2017). Energy Consumption, Carbon Dioxide Emissions and Economic Grouth: the Case of Saudi Arabia. Journal of Renewable Sustainable and Energy,. Vol. 41: 237-247.

3. Asif, M. (2017). Urban Scale Application of Solar PV to Improve Sustainability in the Building and the Energy Sectors of KSA. Journal of Sustainability, Vol. 8: 111. 
4. DesignBuilder. (2008). DesignBuilder Simulation + CFD Training Guide.

5. DesignBuilder. (2009). DesignBuilder User's Manual.

6. Doxiadis (1968). Riyadh Existing Conditions.

7. (KAC) King Abdulaziz City for Atomic and Renewable Energy. (2012). Saudi Arabia 's Renewable Energy Strategy and Solar Energy Deployment Roadmap.

8. Eihissi S. (2012). Studying the Microclimatic Effects of Trees on Thermal Performance of Residential Buildings in the Gaza Strip. Master Thesis, Islamic University of Gaza-Palestine.

9. Listokin, D. \& Walker, C. (1990). The Subdivision and Site Plan Handbook. USA, The Center for Urban Policy Research.

10. Philpy, J. (1959). Riyadh: Ancient and Modern . Middle East Journal Vol. 13.

11. Saudi Electricity Company (SEC) (2009). Annual Report.

12. Susilawati, C. (2011).Challenges Facing Sustainable Housing in Saudi Arabia: A Current Study Showing the Level of Public Awareness. The 17th Pacific Rim Real Estate Society Conference Gold Coast, Australia. 